WORKING PAPER · NO. 2021-18

\title{
Tax Refund Uncertainty: Evidence and Welfare Implications
}

Sydnee Caldwell, Scott Nelson, and Daniel Waldinger

FEBRUARY 2021

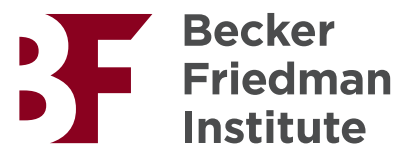




\title{
Tax Refund Uncertainty: Evidence and Welfare Implications*
}

\author{
Sydnee Caldwell
}

UC Berkeley
Scott Nelson

Chicago Booth

\author{
Daniel Waldinger
}

NYU

January 5, 2021

\begin{abstract}
Transfers paid through annual tax refunds are a large but uncertain source of income for poor households. We document that low-income tax-filers have substantial subjective uncertainty about these refunds. We investigate the determinants and consequences of refund uncertainty by linking survey, tax, and credit bureau data. On average, filers' expectations track realized refunds. More uncertain filers have larger differences between expected and realized refunds. Filers borrow in anticipation of their refunds, but more uncertain filers borrow less, consistent with precautionary behavior. A simple consumption-savings model suggests that refund uncertainty reduces the welfare benefits of the EITC by about 10 percent.
\end{abstract}

${ }^{*}$ Caldwell: $\quad$ scaldwell@berkeley.edu; Nelson: scott.nelson@chicagobooth.edu; Waldinger: danielwaldinger@nyu.edu. Special thanks go to the City of Boston Office of Financial Empowerment, including Trinh Nguyen, Constance Martin, Mimi Turchinetz, Brian Robinson, Jason Andrade, and Joanne Evans. Ariel Duong provided invaluable assistance implementing the surveys. We thank Daron Acemoglu, Alex Bartik, Scarlet Chen, Amy Finkelstein, Damon Jones, Olivia Kim, Henrik Kleven, Patrick Kline, Jonathan Kolstad, Ilyana Kuziemko, Pascal Noel, Jonathan Parker, Ricardo Perez-Truglia, Jim Poterba, Antoinette Schoar, Neil Thakral, Owen Zidar, and seminar audiences at MIT, the Federal Reserve Bank of New York, the NTA Annual Conference, the Princeton Public Finance Lunch, and the Washington Center for Equitable Growth Grantee Conference for helpful comments. An earlier version of this paper circulated under the title "Tax Refund Expectations and Financial Behavior." Nelson gratefully acknowledges support from the Washington Center for Equitable Growth. Caldwell, Nelson and Waldinger each thank the George and Obie Shultz Fund at MIT for its support and the National Science Foundation for support under NSF Doctoral Dissertation Research in Economics award No. 1729822. Any opinion, findings, and conclusions or recommendations expressed in this material are those of the authors and do not necessarily reflect the views of the National Science Foundation. 


\section{Introduction}

The tax system is used both to raise revenue and to redistribute income from richer to poorer households. Much of this redistribution is done through large tax credits paid out in annual tax refunds, such as the Earned Income Tax Credit (EITC) and Child Tax Credit (CTC). These credits are a substantial portion of income for many recipients, ${ }^{1}$ but the rules determining these credits are complex. This complexity may lead individuals to be uncertain about their tax liability or refund amount even after other income-related uncertainty is resolved (Chetty et al., 2013; Kleven, 2020).

This paper studies tax refund uncertainty and its welfare consequences among low-income tax filers. We make four contributions. First, we quantify substantial tax-refund uncertainty among low-income filers, and among EITC recipients in particular. Second, we show that despite facing considerable uncertainty, filers have correct mean expectations on average and seem to update their beliefs from year to year in response to new information. Third, we present evidence suggesting that uncertainty may be the result of more complex features of the tax code, such as the phase-in and phase-out regions for tax-based transfer programs or rules for married tax filers. Finally, we show that refund uncertainty distorts individuals' consumption-savings choices and is large enough to cause welfare losses among EITC filers on the order of 10 percent of the value of the EITC.

The starting point for our analysis is a unique survey of tax filer beliefs that we conducted at a Boston Volunteer Income Tax Assistance (VITA) site. The survey elicited filers' expectations and uncertainty just before they filed their taxes, by asking filers what their "best guess" of their refund was, by asking how "certain" they were about that guess, and by asking filers to report the percent chance their refund would fall in six different bins. These probabilistic responses allow us to construct full subjective belief distributions over refund outcomes and obtain quantitative measures of subjective uncertainty (Engelberg et al., 2009). We link the survey to administrative tax data for the tax returns filed at the VITA site, to a panel of filers' credit reports, and to a demographic survey.

Refund uncertainty is large in both absolute and relative terms, roughly 4.5 times larger than prior estimates of transitory income uncertainty (Guvenen et al., 2019). A quarter of filers in our sample report that they are, at the time of tax filing, not at all certain that their refund will fall within a $\$ 1,000$-interval around their best guess. The median filer's subjective standard deviation is more than one quarter the size of their expected refund amount.

Despite reporting substantial uncertainty, filers' beliefs are highly predictive of the re-

\footnotetext{
${ }^{1}$ The typical EITC recipient sees an average refund equal to $12 \%$ of their annual income (Jones, 2012). As noted by Gelman et al. (2019), EITC filers' refunds are necessarily large because the EITC cannot be claimed in advance.
} 
funds they receive: mean expectations closely track average realizations. This is not simply because filers remember last year's refund; expectations also strongly predict changes in their refund relative to last year. In fact, we show that filers' beliefs incorporate new information over the course of the year in a manner consistent with Bayesian updating. The level of uncertainty also varies across individuals in sensible ways. More uncertain individuals have larger prediction errors, or differences between realized and expected tax refunds. These patterns suggest that our survey measure of uncertainty corresponds to actual subjective uncertainty.

Correlates of refund uncertainty suggest that tax code complexity may be a contributor to this uncertainty. Tax filers are more uncertain if their income has changed substantially, if they have dependents, and if they are married. Consistent with this uncertainty being related to tax complexity, we show that these groups also experience larger annual changes in their marginal tax rates and refund amounts.

In the last part of the paper, we examine how tax refund uncertainty impacts financial behavior and welfare. Such impacts have two components. First, variability in refund amounts reduces ex-ante welfare for risk-averse filers, apart from any precautionary response. Second, when filers respond to uncertainty with precautionary behavior, such as borrowing less before refund receipt to insure against receiving a small refund, this increases intertemporal variability in consumption even as it helps tax filers reduce within-period uncertainty (Zeldes, 1989; Carroll and Kimball, 1996).

Using a panel of consumer credit reports, we find that uncertainty is reflected in individuals' financial decisions in the months leading up to and following tax filing. Controlling for expected refund size, more uncertain individuals borrow less in advance of filing, consistent with standard precautionary savings models. The pattern is robust to including demographic controls and to instrumenting our measure of subjective uncertainty with two qualitative measures, as well as controlling flexibly for realized refunds and for income.

Finally, using a simple two-period consumption model and a range of assumptions about risk aversion, we find that tax refund uncertainty is large enough to have significant welfare costs. In the model, tax filers are aware of their uncertainty about their tax refund, and they adjust first-period consumption-savings behavior to insure precautionarily against receiving a lower than expected tax refund in the second period. The model suggests the average filer in our sample would be willing to give up roughly $\$ 90$ to remove uncertainty and $\$ 170$ to remove both uncertainty and variability. While these numbers may seem small in absolute terms, for the average tax filer in our sample they are equivalent to 5 and 9 percent of the filer's total refund, respectively; for EITC recipients, the corresponding welfare costs are 9 and 17 percent of EITC credit amounts. Total 2017 EITC payments were $\$ 66$ billion, suggesting 
aggregate welfare losses on the order of $\$ 6-11$ billion annually for EITC recipients. ${ }^{2}$

To our knowledge, this paper is the first to quantify uncertainty about annual tax refunds and estimate its welfare costs. While there is extensive work on limited understanding of and behavioral responses to the tax code, less is known about the extent and costs of resultant tax-related income uncertainty. Prior work has emphasized how individuals may misunderstand the difference between marginal and average tax rates (Rees-Jones and Taubinsky, 2018; Ballard et al., 2017; Fujii and Hawley, 1988) and may be unaware of EITC rules and incentives (Chetty and Saez, 2013; Chetty et al., 2013; Romich and Weisner, 2000; Smeeding et al., 2000). This limited understanding contributes to limited take-up of tax refunds and credits (Abeler and Jäger, 2015; Zwick, 2018) and is thought to dampen labor-supply responses to the EITC (Kleven, 2020). We argue that the welfare cost of filers' refund-related income uncertainty is another quantitatively important channel through which limited tax understanding can cause welfare loss. ${ }^{3}$ We also contribute to work on individuals' limited understanding of their taxes. Prior work has emphasized that this may be due to the costs of acquiring relevant information (Aghion et al., 2017; Chetty et al., 2013; Jones, 2010) or inattention or inertia (Morrison and Taubinsky, 2019; Taubinsky and Rees-Jones, 2018; Feldman et al., 2016; Jones, 2012). Chetty et al. (2013) suggest individuals may learn over time about tax system features such as the EITC. Our results highlight that there nonetheless exist high levels of uncertainty among EITC filers, as well as several groups that face relatively complex tax schedules.

Beyond the tax context, this paper joins a growing literature on the consequences of uncertainty about or limited understanding of program rules or benefits in settings such as Social Security (Luttmer and Samwick, 2018), health insurance (Handel and Kolstad, 2015), food stamps (Finkelstein and Notowidigdo, 2019), Medicare prescription drug plans (Abaluck and Gruber, 2011), and FAFSA financial aid applications (Bettinger et al., 2012). This literature has used either experimental variation, self-reported certainty equivalents, or choice data to quantify the consequences of uncertainty and limited understanding. In contrast, we use survey methods to directly quantify subjective uncertainty and its correlates, and we link our measures with ex-post outcomes and data on financial behavior to assess their accuracy and relevance. In this vein, we are related to more recent work on firms' macroeconomic uncertainty by Bloom et al. (2019), Coibion et al. (2018), Coibion et al. (2020) that links measures of firm uncertainty with investment choices and outcomes.

\footnotetext{
${ }^{2}$ We divide by EITC credit in our sample and then scale by total EITC credit among the 27 million households who received any in 2017; a similar exercise would use total refund amount both in our sample and in the population, but the latter is unavailable in public IRS statistics.

${ }^{3}$ Related to measuring uncertainty about tax refunds, a complementary but distinct question is the extent of uncertainty about future changes in tax policy, as studied in Skinner (1988).
} 
The paper proceeds as follows. Section 2 describes the empirical setting and data. Section 3 describes how we translate our survey measures of beliefs into probabilistic distributions and compares belief distributions to the distribution of realized refunds. Section 4 explores heterogeneity in subjective uncertainty and in belief updating. Section 5 uses panel data on credit reports to investigate whether filers engage in precautionary savings. It then uses a simple model to calculate the welfare losses associated with refund uncertainty and variability. Section 6 concludes.

\section{Data and Empirical Setting}

Our analysis relies on a unique combination of administrative tax data, credit bureau data, and survey data on refund expectations. The data are collected through one of the largest Volunteer Income Tax Assistance (VITA) tax preparation centers in Boston, MA.

\subsection{The Tax Site}

Boston residents in 2016 were eligible to receive free tax preparation services at the tax site if they worked in the prior year, earned less than $\$ 54,000$, and did not own their own business. At the site, tax filers typically go through three stations. First, they complete an intake survey, which includes questions on demographics and savings behavior. Second, they are offered a free "financial check-up" from a volunteer "financial guide." The guide offers the filer a free credit report and provides information on city services. ${ }^{4}$ Finally, a tax preparer electronically prepares and submits the filer's tax return.

We partnered with the tax site to field a survey of tax filers' expectations about their refund (detailed in Appendix B.1) at the second of the three stations. The survey therefore measures filers' refund uncertainty just before tax preparation and filing. We view this as ideal timing: filers had not yet received any direct information about their refund, but uncertainty about pre-tax income had been resolved, and any efforts to reduce refund uncertainty - such as understanding their withholding, tax liability, and credit eligibility - had already been made. Research consent was also provided at this stage. Figure A1 describes the sequence of data collection at the site.

Because of financial guide shortages, many filers skipped the financial check-up during busy periods. As a result, we obtained consent from only $60 \%$ of tax filers at the site.

\footnotetext{
${ }^{4}$ The site implemented a randomized controlled trial in 2016 where some filers were given a detailed explanation of their credit report and financial advice. We control for treatment status in our analysis of borrowing behavior. An analysis by Navin Associates (2017) shows the treatment and control groups are balanced.
} 
Because consent rates were high (96\%) among filers who did access the financial check-up station, we do not believe consent was a major source of selection into our research sample.

\subsection{Elicitation and Demographic Surveys}

We elicited beliefs in two ways. First, we directly asked each filer for a point estimate of their refund amount. We also asked them if they were "sure," "very sure," or "not at all sure" that the refund would fall within a \$1,000-interval around their best guess. Second, we elicited probabilistic beliefs by asking individuals the probability that their refund would fall within each of six bins: negative (they would have taxes due), $\$ 0-\$ 500, \$ 500-\$ 1,000$, $\$ 1,000-\$ 2,500, \$ 2,500-\$ 5,000$, and over $\$ 5,000$. We designed these bins based on prior-year tax data so that roughly an equal number of actual refunds would fall in each bin, with a smaller number in the two tail bins (see Appendix B.1 for details). We asked for points in a probability mass function rather than moments such as the mean and variance because subjective probabilities may be easier for respondents to understand and calculate (Manski, 2004; Morgan and Henrion, 1990). Section 3 describes how we fit parametric probability distributions to these elicited probabilities in order to calculate each filer's subjective mean and standard deviation.

We obtained information on tax filers' demographic characteristics and financial assets from the intake survey, which nearly ninety percent of filers at the site completed.

\subsection{Administrative Tax and Credit Data}

We link the survey data to tax return data for consenting tax filers. ${ }^{5}$ These data include information on income, filing status, number of dependents, and refund amount. We also observe prior-year tax returns for individuals who previously used the site's tax preparation services, nearly sixty percent of our core sample.

We merge these administrative tax records with a short panel of consumer credit reports for tax filers who provided consent. We have four reports for each individual in our sample: one pulled when they visited the tax site, and three pulled one, two, and six months later.

\subsection{Descriptive Statistics}

Our core analysis sample consists of 618 filers who both completed the tax refund expectations survey and filed their taxes at the site during the spring of 2016. Their characteristics

\footnotetext{
${ }^{5}$ All data are accessed on-site through the data partner. No statistics representing fewer than 10 tax returns are provided to researchers outside the partner.
} 
are described in column 1 of Table 1 and in Table A1. Most filers are unmarried, twentyseven percent file as a single head of household, and thirty-two percent have dependents. Eighty-two percent of filers have at least a high school degree, but only fifteen percent have attended college. The average age is forty years, and the average annual adjusted gross income (AGI) is about $\$ 21,000$.

Tax refunds are large relative to income, savings, and debt levels. The mean refund of $\$ 1,542$ in our core sample is nearly seven percent of the mean AGI and about triple the average savings balance. ${ }^{6}$ For the 35 percent of filers who received the EITC, the average refund is nearly $\$ 1700$, about half of which comes from the EITC itself. The remaining columns in Table 1 present descriptive statistics for filers who completed the demographic survey (column 2), for whom we have prior-year tax returns (column 3), and for whom we have credit report data (column 4). The economic and demographic statistics in the table are largely stable across samples, suggesting that attrition across surveys and data sources is largely unrelated to tax status or demographic characteristics.

Our main analysis samples exclude outlier observations that correspond to filers who reported extreme levels of tax refund uncertainty or income realizations, or whose elicited beliefs were internally inconsistent. Table A1 compares this sample with the complete set of tax filers, both overall and in the subset of filers for whom we have prior year tax information and credit data. ${ }^{7}$

Filers report substantial uncertainty about their refund amounts. Table 2 describes filers' subjective probability distributions overall and by demographic subgroups. Seventy-eight percent of respondents put positive probability on more than one bin. Of those, half put positive probability on exactly two bins, the remaining on three or more. These patterns are stable across filers regardless of whether they are filing with dependents, are married, have a college education, or are above twice the federal poverty level. Responses to the qualitative survey question also indicate uncertainty. A majority of filers (66 percent) are "Somewhat Certain" or "Not Certain At All," rather than "Very Certain," that their refund will fall within a $\$ 1,000$-interval around their best guess. This holds for every subgroup reported in Table 2, with 55 to 70 percent reporting they were not "Very Certain." It is worth noting that

\footnotetext{
${ }^{6}$ Savings data are elicited using the intake survey question, "If you have bank account(s), how much money do you regularly keep in it (them) all together?" Respondents chose either $\$ 0, \$ 1, \$ 100, \$ 101-\$ 500, \$ 501$ $\$ 1,000$, or More than $\$ 1,000$. We mapped intervals to their midpoints, and "More than $\$ 1,000$ " to $\$ 1,500$.

${ }^{7}$ Outlier observations are individuals with subjective uncertainty (the standard deviation of fitted beliefs) in the top or bottom $1 \%$ of respondents, or tax refund prediction errors in the top or bottom $1 \%$, as well as individuals with adjusted gross incomes below 0 . Internally inconsistent beliefs either had a point forecast that fell outside the support of the bins used to report subjective probabilities, or had subjective probabilities that did not sum to $100 \%$. We also include in this category a few individuals whose subjective probabilities did not have contiguous support.
} 
all subgroups report significant uncertainty despite expecting very different refund amounts on average. Filers with dependents expect to receive refunds nearly four times as large as filers without dependents (\$3,520 vs $\$ 837$ ), and filers who are married and above twice the poverty level expect refunds roughly 50 percent larger than other filers.

\section{Tax Filer Beliefs}

This section describes how we translate the survey responses of the site's tax filers into smooth probability distributions and describes the features of these distributions. Although tax filers reported substantial uncertainty about their refunds, their mean expectations were, on average, correct. This is not simply because refunds do not change from year to year; individuals' forecasts closely tracked realized amounts even after conditioning on the prior year return. At the same time, filers report substantial uncertainty. Ex-post, more uncertain filers made larger prediciton errors - defined as gaps between their mean expected refund and their actual refund - suggesting that beliefs are well-calibrated on average.

\subsection{Fitting Belief Distributions}

We convert individuals' probabilistic beliefs into smooth probability distributions following Engelberg et al. (2009). Doing so uses all information available in respondents' subjective probabilities while smoothing between points of the cumulative density function in a reasonable way. Our main estimates fit the elicited bin probabilities to normal distributions to be consistent with the updating model specification in Section 4.2. In Appendix Section E we show that our results are robust to fitting beta distributions, which are also common in the subjective expectations literature (Engelberg et al., 2009). ${ }^{8}$

To fit a normal distribution to each tax filer's elicited beliefs, we penalize the distance between the quantiles of their reported cumulative distribution and those of a normal distribution. Because a normal distribution has full support while the elicited probabilities are over a finite support, we penalize mass in excess of a certain amount $\alpha$ outside of the bin's assigned positive mass. We report results for $\alpha=.01$ because some filers reported bin probabilities down to the precision of a single percentage point. We treat the filer's "best guess" of their refund as their subjective mean.

Formally, let $\mathcal{X}$ denote the interior support points of the response to the probabilistic survey question, and $p_{x}$ denote the reported cumulative probability at each interior point

\footnotetext{
${ }^{8}$ This is not surprising because the means and standard deviations from fitted normal and beta distributions track each other closely. These are the only moments in our regressions. Other research fitting beliefs to normal distributions includes Wiswall and Zafar (2014).
} 
$x \in \mathcal{X}$. Let $(\underline{x}, \bar{x})$ be the minimum and maximum support points. We find the $\left(\hat{\mu}_{i}, \hat{\sigma}_{i}\right)$ for the elicited distribution from each individual $i$ which solves,

$$
\min _{\mu, \sigma} \sum_{x \in \mathcal{X}_{i}}\left[p_{x, i}-\Phi\left(\frac{x-\mu}{\sigma}\right)\right]^{2}+\left(\max \left\{0,1+\Phi\left(\frac{x-\mu}{\sigma}\right)-\Phi\left(\frac{\bar{x}-\mu}{\sigma}\right)-\alpha\right\}\right)^{2}
$$

The first term in Equation 1 penalizes deviations between the interior cumulative probabilities reported by the tax filer and the value of a normal CDF; the second term penalizes mass outside the relevant bins in excess of $\alpha$. Appendix E provides additional details on our procedure, describes the analogous procedure for fitting beta distributions, and compares results from the two parametric assumptions.

\section{$3.2 \quad$ Fitted Beliefs and Validation}

Filers expect to receive large refunds relative to annual income, but also face substantial uncertainty. Table 2 shows that the average mean expectation in our main sample is $\$ 1,605$, which is eight percent of average annual income. Subjective uncertainty is large in absolute terms - the mean of individuals' standard deviations is $\$ 426$ - and is also substantial relative to labor income uncertainty. The baseline estimates in Guvenen et al. (2019), for example, imply that the standard deviation of transitory income shocks for a typical worker each year is six percent of income. ${ }^{9}$ The median filer perceives their refund as having a standard deviation equal to twenty-seven percent of expected refund size and two percent of annual pre-tax income.

These patterns are qualitatively robust to alternative samples and distributional assumptions. The second column of Appendix Table A3 shows that subjective means and standard deviations are similar if we exclude filers who put equal $(50 / 50)$ probability on two bins. Furthermore, assuming normal distributions may yield a conservative estimate of subjective uncertainty; the second group of columns in Table A3 shows results assuming beliefs follow beta and triangular distributions instead of normal distributions, a standard assumption in the literature. The subjective standard deviations are fifty percent larger under this alternative.

We now verify that tax filers provided meaningful answers to the probabilistic survey questions by comparing subjective beliefs to received refunds. The blue binned scatterplot in Panel B of Figure 1 shows that, on average, mean expectations closely track realized refunds. The slope of the regression line is close to one, though respondents with the most

\footnotetext{
${ }^{9}$ See column 8 of their Table IV.
} 
extreme realizations had slightly less extreme expectations. Panel A of Figure 1 shows the kernel density plots of the realized refund amounts and mean expectations are strikingly similar.

Beliefs do not simply track realized refunds because individuals receive the same refund each year. The purple line in Panel B of Figure 1 shows the same binned scatterplot controlling for prior-year refund. There is still a strong positive relationship between the residual variation in expected refunds and realized refunds. This suggests that tax filers' beliefs incorporate additional information about changes in refunds relative to prior years.

Tax filers' reported uncertainty is also consistent with the distribution of realizations. Figure 2 shows that more uncertain individuals see larger gaps between their expected and realized refund. The slope of the line should not necessarily be one - a standard deviation is the square root of the expected squared error, not the expected absolute error. However, the strong positive correlation suggests that differences in uncertainty across filers are reflected in their reported beliefs. Many filers see large expectation errors; roughly a quarter of expectation errors are more than $\$ 1500$.

The comparison between elicited beliefs and refund realizations validate the answers to the probabilistic survey question. Filers' answers predict what actually happened, suggesting their reports contain real information about their beliefs, and that the normal parametric model accurately summarizes key moments of these beliefs. Furthermore, while many tax filers still faced substantial refund uncertainty at the time of filing, they were generally aware of how much uncertainty they faced.

\section{Belief Heterogeneity}

This section investigates belief heterogeneity as a first step toward understanding the underlying mechanisms driving refund uncertainty. We first describe which types of tax filers report the greatest uncertainty, showing patterns consistent with tax code complexity being a driver of uncertainty. We then show that filers incorporate new information about their current-year refund in a manner consistent with Bayesian updating, albeit with significant heterogeneity in updating rates. This heterogeneity in updating rates is consistent with tax filers exerting more effort to understand their tax situation when the stakes are higher, although we cannot reject other plausible explanations. 


\subsection{Correlates of Subjective Uncertainty and Prediction Errors}

A natural hypothesis is that refund uncertainty is driven by tax code complexity. While our data cannot definitively distinguish alternative mechanisms, we find heterogeneity in subjective uncertainty and prediction errors that is consistent with the tax complexity hypothesis.

We regress measures of refund uncertainty and tax circumstances on a range of economic and demographic characteristics. Our specifications take the form

$$
y_{i}=X_{1, i}^{\prime} \beta_{1}+X_{2, i}^{\prime} \beta_{2}+\epsilon_{i} .
$$

$X_{1, i}$ includes characteristics that we term "tax determinants" because they directly affect tax credits or liabilities, such as marital status and number of dependents. $X_{2, i}$ includes other demographics, such as gender and education. Appendix Table A5 shows that the main results are robust to separately controlling for tax determinants or demographic characteristics.

Column 2 of Table 3 presents results from a version of equation 2 where the dependent variable is the standard deviation of an individual's elicited belief distribution. (Column 1 shows sample means for reference.) Filers with dependents have subjective standard deviations $\$ 479$ higher than other filers. Uncertainty is also higher for filers with a larger absolute change in their adjusted gross income (AGI) relative to the preceding tax year. Filers above age 50 are less uncertain, with subjective standard deviations $\$ 140$ lower than otherwise similar filers.

Columns 3 and 4 examine how the same variables are correlated with two proxies for tax complexity: (1) the magnitude of the change in an individual's tax refund relative to the prior year, and (2) the magnitude of the change in an individual's marginal tax rate (MTR) (Gale et al., 2001). ${ }^{10}$ Across both proxies, groups that report higher refund uncertainty also face greater complexity. In particular, the primary recipients of credits such as the EITC and CTC - tax filers with dependents - are exposed to both higher uncertainty and higher complexity.

Column 5 shows that some types of filers reporting greater uncertainty also make larger prediction errors. Prediction errors are $\$ 830$ larger in magnitude for filers with dependents and $\$ 196$ lower for filers over age 50. However, this correspondence does not hold for all filer types; for example, filers whose number of dependents changed since the prior year make larger forecast errors than other filers but do not report greater uncertainty.

\footnotetext{
${ }^{10}$ MTRs are calculated using NBER TAXSIM (Feenberg and Coutts, 1993).
} 


\subsection{Belief Updating}

To further understand potential drivers of refund uncertainty, we investigate whether and how tax filers' expectations reflect new information learned over time. We find that filers incorporate new information in a manner consistent with Bayesian updating, suggesting that uncertainty may reflect access to tax-relevant information. ${ }^{11}$ Furthermore, heterogeneity in how aggressively consumers update their expectations points to a potential role for rational inattention in shaping what new information filers access. ${ }^{12}$

Our analysis in this subsection is micro-founded by a belief updating model, presented in Appendix $\mathrm{C}$, where filers receive potentially noisy signals about this year's refund. Its key prediction is that Bayesian filers should shade their beliefs toward last year's refund on average, assuming that last year's refund informs their prior. More shading corresponds to having a relatively less precise signal about this year's refund. ${ }^{13}$

Motivated by this framework, we regress the difference between an individual's expected refund $\left(m_{1, i}\right)$ and their prior year refund $\left(r_{0, i}\right)$ - we term this difference the filer's "update" on the realized difference $\left(r_{1, i}-r_{0, i}\right)$ between this year's refund and the prior year refund. To study heterogeneity in updating rates within this regression framework, the realized change in refund is also interacted with economic and demographic characteristics $X_{i}$ that we studied in the preceding section, to measure heterogeneity in updating rates across different groups of filers:

$$
m_{1, i}-r_{0, i}=\left(r_{1, i}-r_{0, i}\right) X_{i}^{\prime} \beta+\eta_{i}
$$

The updating rates $X_{i}^{\prime} \beta$ describe how aggressively tax filers with different characteristics update their beliefs toward the actual refund they receive.

Updating rates of 1 would reflect full updating on average, in which average expectations fully reflect how refunds have changed from the prior year. Rates less than 1 reflect partial updating on average, whereas rates greater than 1 would reflect over-reaction to filers' most recent changes in their tax circumstances (Bordalo et al., 2020). While this analysis cannot differentiate which information sources tax filers use to form beliefs - for example, friends or relatives as in Chetty et al. (2013), or recent personal experience as in Kuchler and Zafar

\footnotetext{
${ }^{11}$ Prior work has found evidence that firms, as well as consumers in relatively high-income samples, form beliefs in a Bayesian manner when learning new information (Coibion et al., 2018; Armantier et al., 2016). However, relatively little is known about belief formation in lower-income or lower-SES individuals, even as Das et al. (2020) and Kuhnen and Miu (2017) have pointed to the importance of understanding lower-SES consumers' expectations.

${ }^{12}$ See Coibion et al. (2018) for evidence on such rational inattention in firms' belief updating, or Morrison and Taubinsky (2019) and Taubinsky and Rees-Jones (2018) for evidence on rational inattention in the context of sales taxes.

${ }^{13}$ Even with partial updating (shading) on average, beliefs are unbiased ex-ante on average because the distribution of refund changes is centered at zero for most filer types in our sample.
} 
(2019) or D'Acunto et al. (2020) - our analysis is informative about the extent to which tax filers access and use information that helps move their beliefs closer to their realized refund.

The regression results are reported in Table 4. The estimates are consistent with Bayesian updating in that updating rates lie between 0 and 1. All specifications reported strongly reject the null that individuals do not learn about refund changes and likewise reject both full updating and over-reaction. For example, column 1 shows the average updating rate across all filers is 59.7\%, which is significantly different from both 0 and 1 at the $1 \%$ level. When we explore heterogeneity in subsequent columns, we likewise reject both zero and full updating.

To illustrate the patterns underlying these updating rates, Figure 3 plots the density of individual-level "updates" as a fraction of the actual refund change $\left(r_{1, i}-r_{0, i}\right)$. This distribution shows that most filers (76 percent) update in the direction of their actual refund change: for example, if their refund increased relative to last year, their expected refund is also higher than last year's refund. This distribution is also consistent with Bayesian updating: Bayesian updating would require that more than $50 \%$ of individuals update in the direction of the change in refund; ${ }^{14}$ however, so long as there is noise in the signal, we would not expect all tax filers to do so.

There is also substantial heterogeneity in updating across groups. Filers who saw larger changes in income and larger changes in marginal tax rates (MTRs) update more aggressively. Column 2 of Table 4 indicates that an additional $\$ 1,000$ change in AGI predicts a 1.2 percentage point increase in $X_{i}^{\prime} \beta$. This relationship is statistically and economically significant: the mean absolute AGI change is $\$ 6,120$, with a standard deviation of $\$ 8,780$. A similar relationship holds for marginal tax rates: a 10 percent-point change in MTR predicts a 4.6 percent-point higher updating rate. The mean (standard deviation of) change in MTR is 8.6 (14.7) percentage points. Other variables that predict subjective uncertainty, changes in MTR, and forecast errors - such as age and number of dependents - are less strongly associated with updating rates after controlling for change in MTR.

Columns 3 and 4 estimate the same specification including only tax determinants and demographic variables, respectively. The strong relationships between changes in income or MTR and updating rates continue to hold with only tax controls. Demographic variables weakly predict updating rates even after excluding tax determinants. Overall, we reject no heterogeneity in updating rates in column 3 , where we focus on heterogeneity by tax determinants (the variables denoted $X_{1, i}$ in Table 1 ), but we find no detectable heterogeneity

\footnotetext{
${ }^{14}$ This holds so long as the distribution of signal noise is symmetric. Further statistics on the share of tax filers with various directions and magnitudes of updating rates, both overall and across demographic groups, are shown in Appendix Table A6.
} 
across demographic groups in column $4 .{ }^{15}$

The finding that individuals with larger AGI and MTR changes also update more aggressively is consistent with filers exerting more effort to reduce uncertainty when the stakes are higher, consistent with models of rational inattention (Coibion et al., 2018). We note that these patterns could also be consistent with other changes (e.g., filing status) just being more difficult for tax filers to understand.

\section{Consequences of Refund Uncertainty}

In this section we assess the consequences of refund uncertainty for financial behavior and welfare. We first illustrate the importance of precautionary motives in this population using linked data from a panel of credit reports. We show that more uncertain individuals indeed borrow less prior to refund receipt, consistent with precautionary behavior. Motivated by this result, we then use a simple calibrated model that incorporates both risk aversion and a precautionary motive to calculate the welfare costs of refund uncertainty, under a range of preference parameters.

\subsection{Evidence of Precautionary Behavior}

If tax filers behave precautionarily toward expected tax refunds, filers who have greater refund uncertainty will borrow less out of their expected refund in advance. Similar to precautionary saving, this reduced borrowing insures uncertain filers against the risk of a smaller than expected refund realization (Zeldes, 1989; Carroll and Kimball, 1996).

We test for such precautionary behavior using our panel of credit report data. We use the amount of debt repaid after refund receipt as a proxy for how much a filer borrowed out of their refund before filing. Specifically, we focus on changes in non-installment debt balances between just prior to filing and two months post-filing, by which time a filer should have received their refund. ${ }^{16}$ A negative change in balances (i.e. a decrease in debt) indicates that the filer repaid debt shortly after tax refund receipt.

While we do not observe consumption or the timing of ex-ante borrowing directly, this form of borrowing allows households to smooth consumption out of their refund across time.

\footnotetext{
${ }^{15}$ We do not see significant heterogeneity by education. Prior work by D'Acunto et al. (2019) found that higher IQ (but not more educated) Finnish men responded more in terms of consumption in response to policy changes.

${ }^{16}$ Non-installment debt is predominantly credit card debt, which, unlike installment debt such as student loans, can be adjusted relatively easily over short time horizons. Credit card debt is a primary means of consumption smoothing for low-score consumers (Fulford, 2015), among whom over ninety percent of credit card holders borrow on credit cards (Nelson, 2020).
} 
If more uncertain households are less likely to engage in such borrowing due to precautionary motives, refund uncertainty may lead them to under-consume prior to refund receipt.

\subsubsection{Main Results}

We estimate regressions of the form

$$
\Delta B_{i}=\omega m_{1, i}+\gamma \sigma_{i}+X_{i}^{\prime} \beta+\epsilon_{i}
$$

where $\Delta B_{i}$ denotes the change in balance; $m_{1, i}$ is the filer's mean refund expectation; and $\sigma_{i}$ is the standard deviation of their elicited belief distribution. The key parameter of interest is $\gamma$. A positive estimate is consistent with precautionary behavior. $X_{i}$ includes economic and demographic controls which may affect filers' borrowing or capture heterogeneity in preferences over time and risk. The identifying assumption is that unobserved determinants of the change in balances are uncorrelated with $\sigma_{i}$ conditional on the included covariates. To reduce the influence of outliers we winsorize the dependent variable at the $5 \%$ level. ${ }^{17}$

Table 5 presents regression estimates from equation 4 and related specifications. The first column shows a univariate model with only the first term in equation 4, filers' mean refund expectations $m_{1, i}$. Column 2 adds subjective uncertainty; column 3 adds demographic controls; and column 4 adds controls for tax determinants. ${ }^{18}$

The negative estimates in the first row of Table 5 show that filers who have higher mean refund expectations indeed borrow more ex-ante. ${ }^{19}$ The positive estimates of $\sigma_{i}$ are evidence of precautionary behavior: filers with higher subjective standard deviations of their refund expectations borrow less ex-ante. The estimates imply that, for a given expected refund, a $\$ 1000$ increase in the subjective standard deviation leads individuals to borrow over $\$ 200$ less before filing. The coefficient on uncertainty remains virtually unchanged moving across columns 2-4. ${ }^{20}$ Figure A4 depicts a binned scatterplot corresponding to the regression in column 4.

\footnotetext{
${ }^{17}$ Specifically, the ninety-fifth percentile value of the dependent variable is assigned to observations with values above the ninety-fifth percentile (and similarly for values below the fifth percentile). We show robustness to winsorizing at the $1 \%$ level in Column 9 of Table 6.

${ }^{18}$ The tax determinants include indicators for being married, having dependents, and receiving unemployment insurance; the demographic controls indicate whether a filer is female, over 50, or a college graduate. We discuss these controls in Section 4.1.

${ }^{19}$ The estimates of $\omega$ are close to Baugh et al. (2020)'s estimate that $13 \%$ of tax refunds are used for debt repayment or savings; see their Table 4.

${ }^{20}$ We estimate the same regression at a six-month rather than two-month horizon and cannot reject equality between the two-month and six-month estimates. While this test is low-powered given our sample size, it is consistent with our qualitative findings not being driven by unobserved heterogeneity. For other evidence using subjective expectations data to test for precautionary behavior, see for example Ben-David et al. (2018), Christelis et al. (2018), Jappelli and Pistaferri (2000), or Guiso et al. (1996).
} 


\subsubsection{Robustness of Borrowing Results}

Tables 6 and A7 present results from a series of robustness checks.

Mismeasurement of Uncertainty We first address the concern that there is measurement error in $\sigma_{i}$ by running two-stage least squares models where we instrument for $\sigma_{i}$ using our qualitative measures of uncertainty, as reported in Table 5 columns 5-7. The first stage results, presented in the bottom panel, confirm that individuals who report they are "somewhat sure" or "very sure" of their refund amount have smaller measures of $\sigma_{i}$ than those who report they are "not sure at all," even after controlling for demographic characteristics and tax determinants. The fact that the coefficient on $\sigma_{i}$ is larger in the 2SLS specifications presented in columns 5-7 than in the corresponding OLS estimates in columns 2-4 suggests that our estimates of the importance of precautionary behavior may be conservative (i.e., biased toward zero).

We present another series of checks that address potential measurement error in columns 2-6 of Appendix Table A7, which is further described in Appendix Section E. These results show that our qualitative findings are robust to considering measures of beliefs that were computed by fitting beliefs to beta (rather than normal) distributions.

Errors in the Dependent Variable We use $\Delta B_{i}$ - the post-refund change in noninstallment balances - as a proxy for pre-refund borrowing. Classical measurement error in $\Delta B_{i}$ would simply lead to larger standard errors. However, if individuals endogenously self-insure against low refund realizations through channels not observed in credit report data, $\Delta B_{i}$ may not be a reasonable proxy for pre-refund borrowing. This would occur if, for example, individuals change their savings or their hours worked in response to tax refund uncertainty.

We address this concern by examining two sub-populations that are less likely to have savings and by examining filers who indicated in our survey data that they are unable to change their labor income when desired. Column 2 of Table 6 presents results for filers that did not choose to receive their refund via direct deposit. These individuals may use their savings accounts less heavily, or may not have savings accounts. Column 3 focuses on individuals who, on the demographics and assets survey, either reported that they did not have a savings account, or that they had less than $\$ 100$ in such an account. Both columns show the same, positive relationship between uncertainty and borrowing: uncertain individuals borrow less prior to refund receipt, indicating that they spent less of their refund before the resolution of uncertainty. Column 4 of Table 6 shows we obtain similar results in the subpopulation of individuals who indicated in our survey data that they are unable to 
change their labor income when desired.

Table A7 shows that we obtain the same positive relationship between uncertainty and borrowing in these 3 subgroups when using the alternative beta-distribution measure of beliefs, as described further in Appendix Section E. Column 9 of Table 6 shows that we obtain similar results when we winsorize the dependent variable at the $1 \%$ level, rather than the $5 \%$ level.

Omitted Variables Bias Finally, we address the concern that our results may reflect unobserved heterogeneity across filers. Such heterogeneity would have to generate a positive correlation between uncertainty and changes in borrowing over time in the absence of a causal channel from uncertainty to changes in borrowing.

Column 5 of Table 6 shows that we obtain qualitatively similar results when we restrict our sample to those without dependents, as having dependents is one of the main correlates of uncertainty in our sample. The remaining columns in this table address the concern that those with high levels of uncertainty are simply those that receive small refunds. Columns 6 8 add additional controls for refund and income, two of the main determinants of borrowing behavior. Column 6 adds a linear control for the received refund amount. Column 7 adds a linear control for AGI. Column 8 adds a third-order polynomial in both refund and AGI. The coefficient on uncertainty remains positive, and is stable across specifications. This is consistent with precautionary behavior, rather than unobserved heterogeneity, being the main driver of our results.

\subsection{Welfare Costs}

Motivated by the evidence that uncertainty may affect consumption smoothing through borrowing behavior, we use a simple calibrated model to quantify the welfare cost of uncertainty. This exercise does not depend directly on the estimates in the prior section, given the strong assumptions required to directly estimate households' preferences. Instead, we report welfare costs for a range of standard preferences.

We consider a two-period model where households make $t=0$ borrowing decisions with uncertainty about $t=1$ income. Households have two income sources: known take-home pay $c$ received in both periods, and tax refunds $y$ received in $t=1$. At $t=0$, the household's belief about their refund is given by $F(y)$. They can borrow or save at rate $R$ and choose debt $b$ to maximize their expected discounted utility, yielding ex-ante welfare

$$
V^{u} \equiv \max _{b} u(c+b)+\beta \int_{y} u(c+y-R b) d F(y)
$$


By comparison, a household that knows $y$ can adjust their $t=0$ debt in anticipation of their actual refund. Their ex-ante welfare is

$$
V^{n u} \equiv \int_{y}\left[\max _{b} u(c+b)+\beta u(c+y-R b)\right] d F(y)
$$

In the no-uncertainty case, the household still faces refund variability, perhaps due to changes in tax policy or income shocks not fully realized by the end of the year. To benchmark the welfare cost of uncertainty, we consider the deterministic case where each household receives a refund equal to their mean expectation:

$$
V^{d} \equiv \max _{b} u(c+b)+\beta u\left(c+\int_{y} y d F(y)-R b\right)
$$

A predictable policy such as universal basic income would affect households' income processes similarly to the deterministic case.

This setup abstracts away from a number of issues that likely lead us to underestimate the welfare cost of refund uncertainty. Refund-related uncertainty and variability exist on top of other sources of income variability - for example, the possibility of an employment or health shock - leading us to underestimate the likelihood of states with a high marginal utility of income. Furthermore, our welfare calculations ignore any costly effort households exert to learn about their tax liability. We only consider the welfare loss from uncertainty that remains after filers have spent time and effort reducing their ex-ante uncertainty.

On the other hand, we may overstate welfare costs if we underestimate filers' abilities to smooth consumption. Empirical evidence that low-income households have low savings and cannot fully consumption smooth even for small shocks (Federal Reserve Board, 2019) suggests that our model may be a reasonable approximation. Nevertheless, some households may be able to smooth over longer periods. We also assume that households can only smooth out of their own income, instead of borrowing from friends or family. Though we think this is a reasonable benchmark assumption given the evidence of precautionary behavior documented in the previous section, it could also lead us to overstate the welfare cost of uncertainty.

\subsubsection{Compensating Variation}

We measure the welfare cost of uncertainty by computing households' compensating variation: their willingness-to-pay to be in the no-uncertainty and deterministic cases instead of the uncertainty case. Let $C V^{n u}$ be the per-period CV for no uncertainty, and $C V^{d}$ the per-period CV for a deterministic refund. Formally, these are defined implicitly by, 


$$
\begin{aligned}
\int_{y}\left[\max _{b} u\left(c_{0, i}+b-C V_{i}^{\mathrm{nu}}\right)+\beta u\left(c_{1, i}+y-R b-C V_{i}^{\mathrm{nu}}\right)\right] d F_{i}(y) & =V_{i}^{u} \\
\max _{b} u\left(c_{0, i}+b-C V_{i}^{\mathrm{d}}\right)+\beta u\left(c_{1, i}+\int_{y}[y] d F_{i}(y)-R b-C V_{i}^{\mathrm{d}}\right) & =V_{i}^{u}
\end{aligned}
$$

We interpret $C V^{*}$ as the per-period cost of refund uncertainty. Because this allows the household to re-optimize $b$ given $C V$, it is likely a conservative estimate.

We take a period to be one quarter. To compute $C V^{*}$ for each tax filer, we need information on preferences $\{u(),. \beta\}$, take-home pay $c$, beliefs $F($.$) , and the interest rate R$. Elicited beliefs provide a measure of $F($.$) . Take-home pay, c$, comes from tax returns and is held fixed across realizations of $y$. Following the literature estimating risk aversion in insurance markets (Brown and Finkelstein, 2008), our preferred specification assumes constant relative risk aversion utility with $\gamma=3$. In robustness checks we consider alternative values of $\gamma$. We assume individuals discount the future at $\beta=.98$ and face a quarterly interest rate of $R=1.05$, a reasonable approximation of the cost of typical non-installment debt like credit cards (Nelson, 2020). Appendix D provides details about how $C V^{d}$ and $C V^{n u}$ are calculated. Our reported estimates scale CV to equal the total, not per-period, compensation required to make individuals as well off as they are in the no-uncertainty or deterministic benchmark.

\subsubsection{Welfare Losses}

Figure 4 presents the mean CV across filers assuming CRRA utility with $\gamma$ (the coefficient of relative risk aversion) equal to 3 . The average filer would give up $\$ 93$ per year to eliminate tax refund uncertainty, more than 5 percent of the average tax refund in our sample. The mean $C V^{n u}$ is $\$ 165$ per year for EITC filers, $\$ 179$ for filers with above-median uncertainty, and $\$ 108$ for households earning below 200 percent of the federal poverty level. Losses are large, even for filers whose tax situation has not changed; filers who have the same filing status and number of dependents as the year before have mean losses of $\$ 95 . C V^{d}$ is consistently about twice as large as $C V^{n u}$.

Losses are especially large for filers whose refund uncertainty is large relative to income. Column 2 of Table 7 shows that the median $C V^{n u}$ is only $\$ 12$ for all filers and only $\$ 33$ for EITC filers, far lower than the respective means. However, a long right tail of filers face a high cost of uncertainty. The standard deviation of $C V^{n u}$ across filers is consistently two to three times the mean, $\$ 270$ for all filers and nearly $\$ 370$ for EITC filers.

The estimated welfare losses depend on the assumed level of risk aversion. Table 7 compares $\mathrm{CV}$ assuming $\gamma=1$ and $\gamma=5$ to those for $\gamma=3$. With modest risk aversion 
$(\gamma=1)$, mean $C V^{n u}$ is $\$ 24$ per year for all filers and $\$ 42$ per year for EITC recipients. These are about one fourth of the baseline values, but still more than one percent of the value of the EITC. Conversely, with very high risk aversion $(\gamma=5)$, mean $C V^{n u}$ is $\$ 128$ for all filers and $\$ 223$ for EITC filers.

These welfare losses are large relative to the size of the average refund, particularly for EITC recipients; our results suggest welfare costs on the order of $10 \%$ of the value of the EITC. Scaling this by the size of the federal EITC in 2017 suggests aggregate annual welfare costs of \$6-11 billion. Our results show that the structure of the EITC - which provides individuals with a large but uncertain transfer - leads to lower welfare gains than a transfer that is easy to anticipate. These numbers may be useful when comparing the EITC with equally large but certain transfers, such as a universal basic income.

\section{Conclusion}

This paper uses a unique survey of tax filers' refund expectations, linked to administrative tax and credit data, to quantify tax refund uncertainty and estimate its consequences. In

our sample of low-income filers, individuals face substantial uncertainty about the size of their tax refund, even though this refund is often a significant portion of annual income. This uncertainty affects financial decisions: more uncertain filers borrow less before filing, consistent with precautionary behavior. A simple consumption-savings model suggests that refund uncertainty significantly reduces the efficiency of redistribution through the tax code.

Our results establish that tax refund uncertainty is quantitatively important. However, more work is needed to understand underlying mechanisms and their policy implications. Why households fail to resolve uncertainty could inform the design of tax simplification policies and may be important for predicting behavioral responses to, and welfare consequences of, other tax reforms. Tax-related uncertainty may also affect other economic decisions, such as labor supply. Combining survey and administrative data, as our study does, is a promising avenue for future work. 


\section{References}

Abaluck, Jason and Jonathan Gruber, "Choice inconsistencies among the elderly: evidence from plan choice in the Medicare Part D program," American Economic Review, 2011, 101 (4), 1180-1210.

Abeler, Johannes and Simon Jäger, "Complex tax incentives," American Economic Journal: Economic Policy, 2015, 7 (3), 1-28.

Aghion, Philippe, Ufuk Akcigit, Matthieu Lequien, and Stefanie Stantcheva, "Tax Simplicity and Heterogeneous Learning," Technical Report, Harvard University 2017.

Armantier, Olivier, Scott Nelson, Giorgio Topa, Wilbert Van der Klaauw, and Basit Zafar, "The Price Is Right: Updating Inflation Expectations in a Randomized Price Information Experiment," Review of Economics and Statistics, 2016, 98 (3), 503-523.

Ballard, Charles L, Sanjay Gupta et al., "Perceptions and realities of average tax rates in the federal income tax: evidence from Michigan," Technical Report, Working paper (August) 2017.

Baugh, Brian, Itzhak Ben-David, Hoonsuk Park, and Jonathan A Parker, "Asymmetric Consumption Smoothing," Technical Report, National Bureau of Economic Research 2020.

Ben-David, Itzhak, Elyas Fermand, Camelia M Kuhnen, and Geng Li, "Expectations uncertainty and household economic behavior," Technical Report, National Bureau of Economic Research 2018.

Bettinger, Eric P, Bridget Terry Long, Philip Oreopoulos, and Lisa Sanbonmatsu, "The role of application assistance and information in college decisions: Results from the H\&R Block FAFSA experiment," The Quarterly Journal of Economics, 2012, $127(3), 1205-1242$.

Bloom, Nicholas, Philip Bunn, Scarlet Chen, Paul Mizen, Pawel Smietanka, and Gregory Thwaites, "The impact of Brexit on UK firms," Technical Report, National Bureau of Economic Research 2019.

Bordalo, Pedro, Nicola Gennaioli, Yueran Ma, and Andrei Shleifer, "Overreaction in macroeconomic expectations," American Economic Review, 2020, 110 (9), 2748-82.

Brown, Jeffrey R and Amy Finkelstein, "The interaction of public and private insurance: Medicaid and the long-term care insurance market," American Economic Review, 2008, 98 (3), 1083-1102.

Carroll, Christopher D and Miles S Kimball, "On the Concavity of the Consumption Function," Econometrica, 1996, pp. 981-992.

Chetty, Raj and Emmanuel Saez, "Teaching the Tax Code: Earnings Responses to an Experiment with EITC Recipients," American Economic Journal: Applied Economics, 2013, 5 (1), 1-31. 
_, John N Friedman, and Emmanuel Saez, "Using Differences in Knowledge Across Neighborhoods to Uncover the Impacts of the EITC on Earnings," American Economic Review, 2013, 103 (7), 2683-2721.

Christelis, Dimiris, Dimitris Georgarakos, Tullio Jappelli, and Maarten van Rooij, "Consumption Uncertainty and Precautionary Saving," Working Paper, 2018.

Coibion, Olivier, Yuriy Gorodnichenko, and Saten Kumar, "How do firms form their expectations? new survey evidence," American Economic Review, 2018, 108 (9), 2671-2713.

_, _, and Tiziano Ropele, "Inflation expectations and firm decisions: New causal evidence," The Quarterly Journal of Economics, 2020, 135 (1), 165-219.

D’Acunto, Francesco, Daniel Hoang, Maritta Paloviita, and Michael Weber, "Human frictions in the transmission of economic policy," University of Chicago, Becker Friedman Institute for Economics Working Paper, 2019, (2019-07).

_, Ulrike Malmendier, Juan Ospina, and Michael Weber, "Exposure to Grocery Prices and Inflation Expectations," 2020.

Das, Sreyoshi, Camelia M Kuhnen, and Stefan Nagel, "Socioeconomic status and macroeconomic expectations," The Review of Financial Studies, 2020, 33 (1), 395-432.

Engelberg, Joseph, Charles F Manski, and Jared Williams, "Comparing the Point Predictions and Subjective Probability Distributions of Professional Forecasters," Journal of Business 83 Economic Statistics, 2009, 27 (1), 30-41.

Federal Reserve Board, "Report on the Economic Well-Being of US Households in 2018, May 2019," Board of Governors of the Federal Reserve System, Washington, DC, 2019.

Feenberg, Daniel and Elisabeth Coutts, "An introduction to the TAXSIM model," Journal of Policy Analysis and management, 1993, 12 (1), 189-194.

Feldman, Naomi E, Peter Katuščák, and Laura Kawano, "Taxpayer confusion: Evidence from the child tax credit," American Economic Review, 2016, 106 (3), 807-35.

Finkelstein, Amy and Matthew J Notowidigdo, "Take-up and targeting: Experimental evidence from SNAP," The Quarterly Journal of Economics, 2019, 134 (3), 1505-1556.

Fujii, Edwin T and Clifford B Hawley, "On the accuracy of tax perceptions," The Review of Economics and Statistics, 1988, pp. 344-347.

Fulford, Scott L, "How important is variability in consumer credit limits?," Journal of Monetary Economics, 2015, 72, 42-63.

Gale, William G et al., "Tax simplification: issues and options," Tax Notes, 2001, 92 (11), 1463-1483. 
Gelman, Michael, Shachar Kariv, Matthew D Shapiro, and Dan Silverman, "Rational Illiquidity and Consumption: Theory and Evidence from Income Tax Withholding and Refunds," Technical Report, National Bureau of Economic Research 2019.

Guiso, Luigi, Tullio Jappelli, and Daniele Terlizzese, "Income risk, borrowing constraints, and portfolio choice," The American Economic Review, 1996, pp. 158-172.

Guvenen, Fatih, Fatih Karahan, Serdar Ozkan, and Jae Song, "What do data on millions of US workers reveal about life-cycle earnings dynamics?," FRB of New York Staff Report, 2019, (710).

Handel, Benjamin R and Jonathan T Kolstad, "Health insurance for" humans": Information frictions, plan choice, and consumer welfare," American Economic Review, 2015, 105 (8), 2449-2500.

Jappelli, Tullio and Luigi Pistaferri, "Using Subjective Income Expectations to Test for Excess Sensitivity of Consumption to Predicted Income Growth," European Economic Review, 2000, 44 (2), 337-358.

Jones, Damon, "Information, preferences, and public benefit participation: Experimental evidence from the advance EITC and 401 (k) savings," American Economic Journal: Applied Economics, 2010, 2 (2), 147-63.

_ , "Inertia and Overwithholding: Explaining the Prevalence of Income Tax Refunds," American Economic Journal: Economic Policy, 2012, 4 (1), 158-85.

Kleven, Henrik, "The EITC and the Extensive Margin: A Reappraisal," Technical Report, National Bureau of Economic Research 2020.

Kuchler, Theresa and Basit Zafar, "Personal experiences and expectations about aggregate outcomes," The Journal of Finance, 2019, 74 (5), 2491-2542.

Kuhnen, Camelia M and Andrei C Miu, "Socioeconomic status and learning from financial information," Journal of Financial Economics, 2017, 124 (2), 349-372.

Luttmer, Erzo FP and Andrew A Samwick, "The Welfare Cost of Perceived Policy Uncertainty: Evidence from Social Security," American Economic Review, 2018, 108 (2), $275-307$.

Manski, Charles F, "Measuring Expectations," Econometrica, 2004, 72 (5), 1329-1376.

Morgan, Millett Granger and Max Henrion, Uncertainty: a guide to dealing with uncertainty in quantitative risk and policy analysis, Cambridge university press, 1990.

Morrison, William and Dmitry Taubinsky, "Rules of Thumb and Attention Elasticities: Evidence from Under-and Overreaction to Taxes," Technical Report, National Bureau of Economic Research 2019.

Navin Associates, "Wealth Building at Tax Time," https://owd.boston.gov/wpcontent/uploads/2017/07/DES-89-Financial-Check-up-Evaluation-2017-Web.pdf, 2017. 
Nelson, Scott, "Private Information and Price Regulation in the US Credit Card Market," Unpublished Working Paper, 2020.

Rees-Jones, Alex and Dmitry Taubinsky, "Measuring Schmeduling," 2018.

Romich, Jennifer L and Thomas Weisner, "How Families View and Use the EITC: Advance Payment Versus Lump Sum Delivery," National Tax Journal, 2000, pp. 12451265.

Skinner, Jonathan, "The welfare cost of uncertain tax policy," Journal of Public Economics, 1988, 37 (2), 129-145.

Smeeding, Timothy M, Katherin Ross Phillips, and Michael O'Connor, "The EITC: Expectation, Knowledge, Use, and Economic and Social Mobility," National Tax Journal, 2000, pp. 1187-1209.

Taubinsky, Dmitry and Alex Rees-Jones, "Attention variation and welfare: theory and evidence from a tax salience experiment," The Review of Economic Studies, 2018, 85 (4), $2462-2496$.

Wiswall, Matthew and Basit Zafar, "Determinants of College Major Choice: Identification Using an Information Experiment," The Review of Economic Studies, 2014, 82 (2), $791-824$.

Zeldes, Stephen P, "Consumption and Liquidity Constraints: An Empirical Investigation," Journal of Political Economy, 1989, 97 (2), 305-346.

Zwick, Eric, "The Costs of Corporate Tax Complexity," 2018. 


\section{$7 \quad$ Figures and Tables}

Figure 1: Refunds and Fitted Beliefs

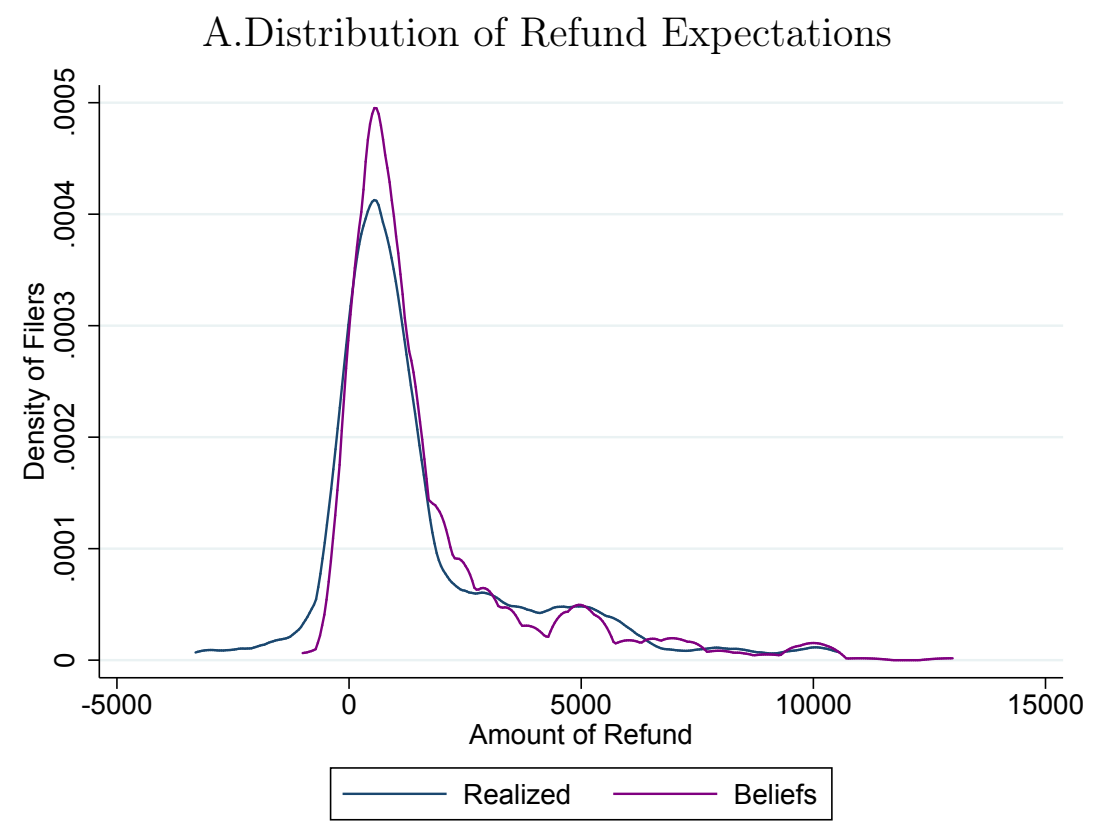

B. Refunds and Expected Refunds

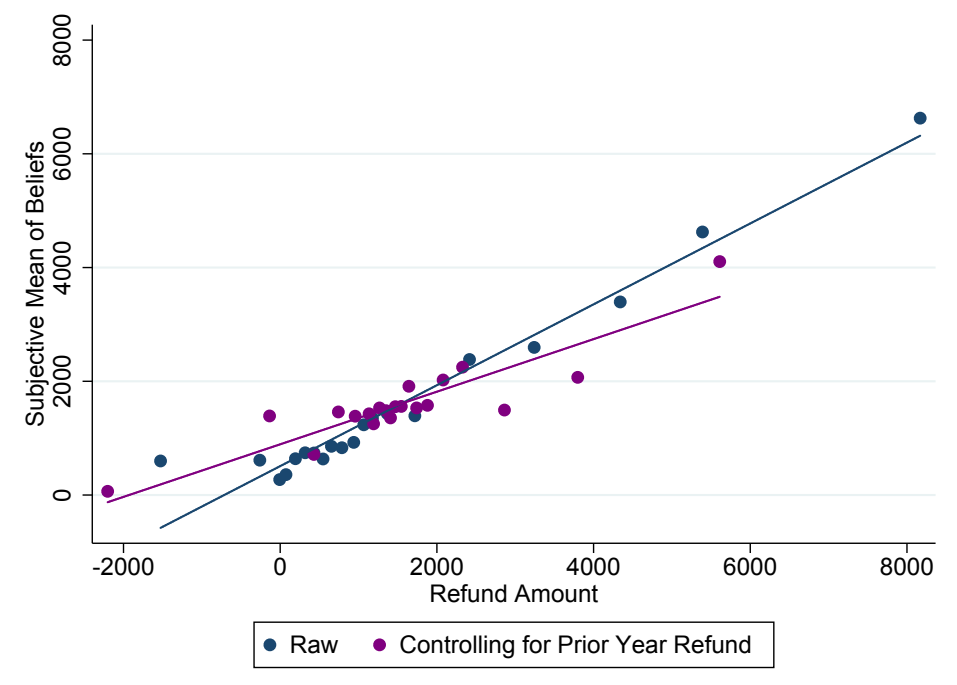

Note: Panel A shows kernel density plots of filers' observed refunds (blue) and mean expectations (purple). The densities were computed using an Epanechnikov kernel with the optimal (Gaussian) bandwidth, which here is $\$ 318$. Panel B shows binned scatterplots of mean expectations against actual refund amounts. The expected refunds are the means of the distributions calculated using the procedure described in Section 3. The blue binned scatterplot corresponds to the unconditional correlation. The purple binned scatterplot was computed after controlling for the amount of the prior-year refund. 
Figure 2: Refund Uncertainty and Prediction Errors

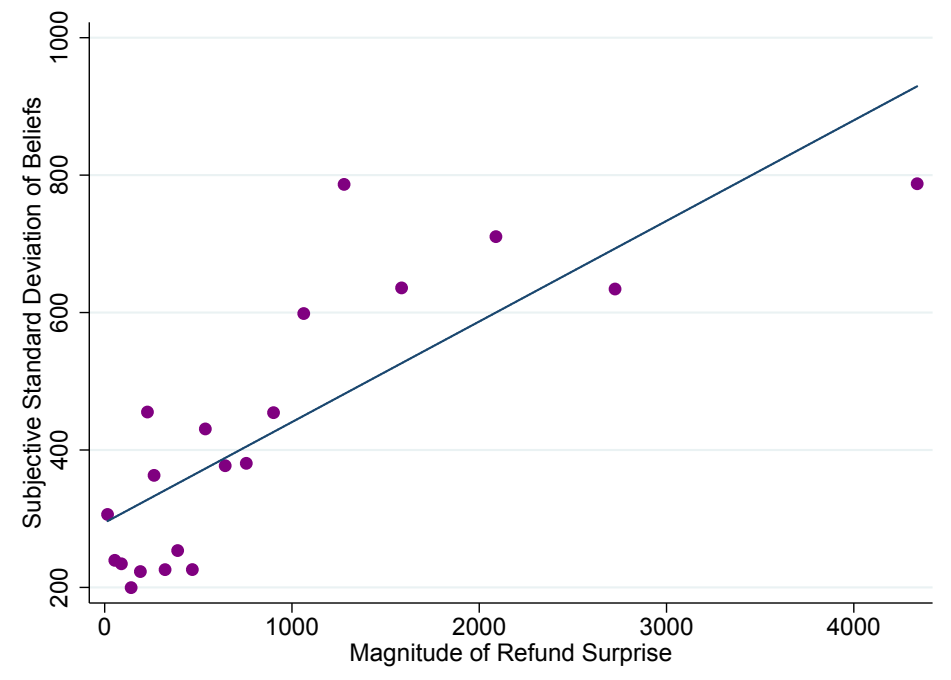

Note: This figure shows a binned scatterplot of the size of each filer's prediction error (actual refund - mean expectation) against the subjective standard deviation of beliefs.

Figure 3: Belief Updating

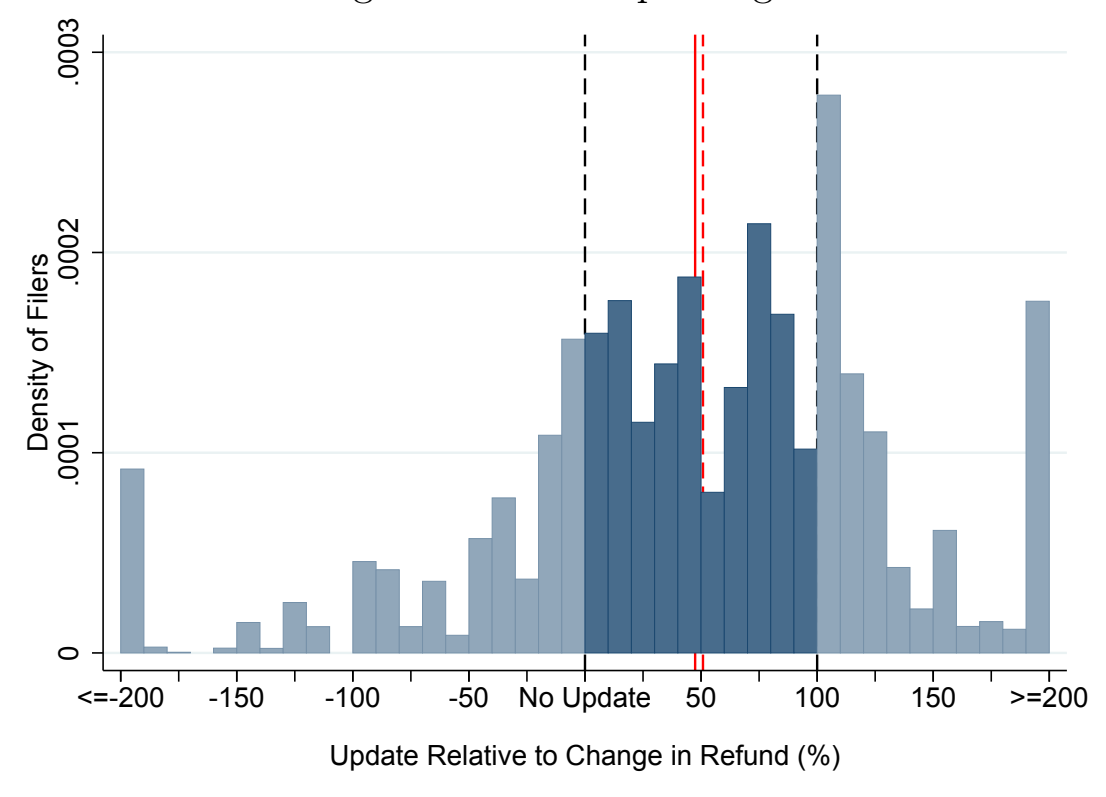

Note: This figure plots the distribution of $\frac{m_{1}-r_{0}}{r_{1}-r_{0}} \times 100$, the amount an individual updates relative to his/her past year refund, as a percentage of the actual changes in refund. Negative values indicate the individual's mean estimate moved (relative to their prior year refund) in the wrong direction. Numbers between 0 and 100 indicate beliefs that fall in between the prior-year refund and the current-year refund, reflecting partial updating. Numbers over 100 indicate beliefs that moved in the same direction as the refund, but which "overshot." Updates are bottom- and top-coded at -200 and 200 percent. Observations are weighted by the size of refund. The solid red line shows the mean and the dashed red line shows the median. 
Figure 4: Compensating Variation by Demographic Group

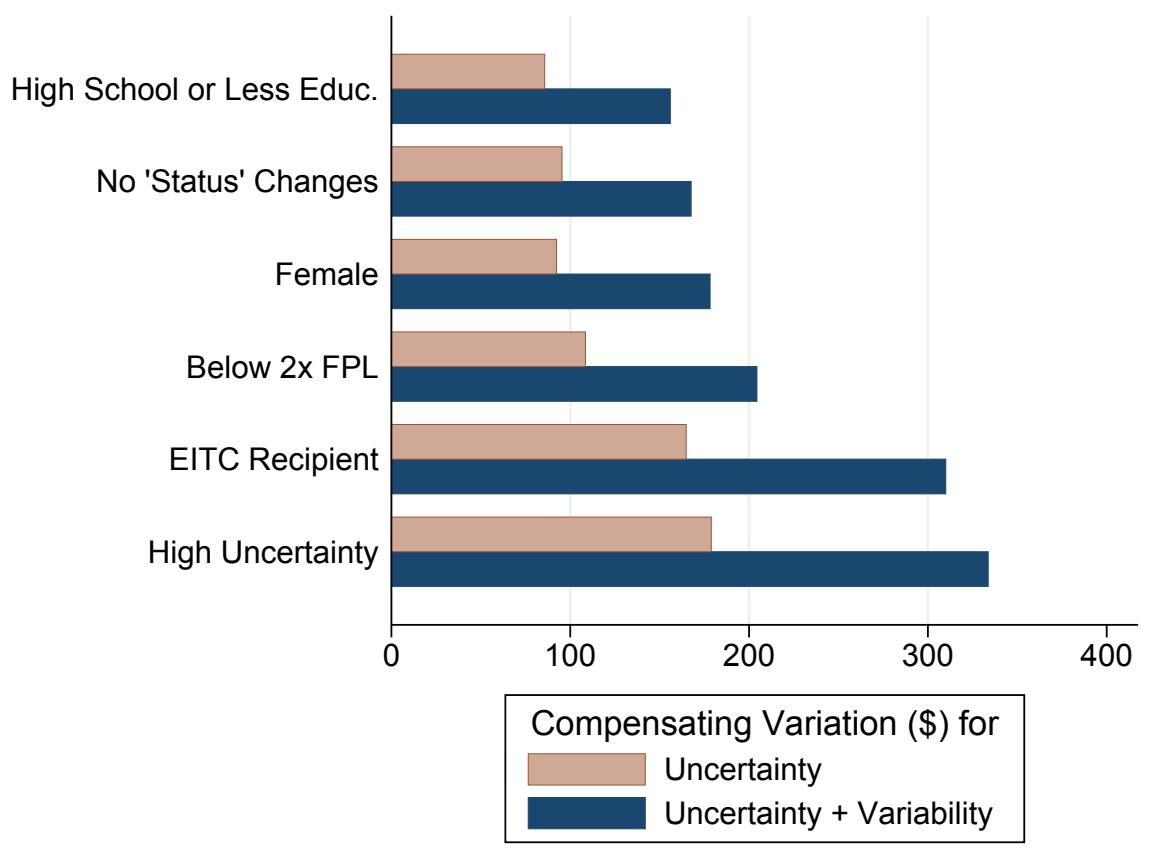

Note: This figure shows the mean compensating variation (CV) for different demographic groups under two scenarios. Under the "uncertainty" (gold) scenario, individuals are given per-period transfers such that they are as well off as they are when they choose debt and consumption levels, knowing their future refund. Under the "uncertainty+variability" (blue) scenario, individuals are given per-period transfers such that they are as well off as they are when they face a deterministic refund equal to the expected refund. These numbers are computed assuming a CRRA utility function with $\gamma=3$. High Uncertainty is defined as having above-median subjective standard deviation, FPL abbreviates federal poverty level, and No 'Status' Changes refers to having the same filing status and number of dependents as in the preceding tax year. More information on how we compute CV is provided in Section 5.2. Results for a wider range of utility functions are presented in Appendix Table 7. 
Table 1: Characteristics of Filers

\begin{tabular}{|c|c|c|c|c|}
\hline & $\begin{array}{c}\text { Tax Data \& } \\
\text { Expectations } \\
\text { Data } \\
(1) \\
\end{array}$ & $\begin{array}{c}\text { Tax Data, } \\
\text { Expectations } \\
\text { Data, \& } \\
\text { Demographics } \\
(2) \\
\end{array}$ & $\begin{array}{c}\text { Current and } \\
\text { Prior Tax Data } \\
\text { \& Expectations } \\
\text { Data } \\
\text { (3) } \\
\end{array}$ & $\begin{array}{c}\text { Tax Data, } \\
\text { Expectations } \\
\text { Data, \& Credit } \\
\text { Data } \\
(4) \\
\end{array}$ \\
\hline \multicolumn{5}{|l|}{ Demographic Characteristics } \\
\hline Female & $\begin{array}{c}0.62 \\
(0.15)\end{array}$ & $\begin{array}{c}0.62 \\
(0.15)\end{array}$ & $\begin{array}{c}0.65 \\
(0.18)\end{array}$ & $\begin{array}{c}0.67 \\
(0.20)\end{array}$ \\
\hline Age & $\begin{array}{c}40.21 \\
(15.92)\end{array}$ & $\begin{array}{c}40.15 \\
(15.82)\end{array}$ & $\begin{array}{c}42.85 \\
(15.70)\end{array}$ & $\begin{array}{c}41.66 \\
(15.87)\end{array}$ \\
\hline BA Degree & $\begin{array}{c}0.15 \\
(0.36)\end{array}$ & $\begin{array}{c}0.15 \\
(0.36)\end{array}$ & $\begin{array}{c}0.18 \\
(0.38)\end{array}$ & $\begin{array}{c}0.20 \\
(0.40)\end{array}$ \\
\hline \multicolumn{5}{|c|}{ Economic and Tax Characteristics } \\
\hline Adjusted Gross Income (\$) & $\begin{array}{c}20,637 \\
(15,930)\end{array}$ & $\begin{array}{c}20,705 \\
(15,752)\end{array}$ & $\begin{array}{c}23,475 \\
(16,228)\end{array}$ & $\begin{array}{c}24,081 \\
(16,356)\end{array}$ \\
\hline Has Dependents & $\begin{array}{c}0.32 \\
(0.47)\end{array}$ & $\begin{array}{c}0.32 \\
(0.47)\end{array}$ & $\begin{array}{c}0.36 \\
(0.48)\end{array}$ & $\begin{array}{c}0.34 \\
(0.47)\end{array}$ \\
\hline Married & $\begin{array}{c}0.08 \\
(0.27)\end{array}$ & $\begin{array}{c}0.07 \\
(0.26)\end{array}$ & $\begin{array}{c}0.07 \\
(0.25)\end{array}$ & $\begin{array}{c}0.08 \\
(0.28)\end{array}$ \\
\hline Lost Job & $\begin{array}{c}0.08 \\
(0.27)\end{array}$ & $\begin{array}{c}0.07 \\
(0.26)\end{array}$ & $\begin{array}{c}0.07 \\
(0.25)\end{array}$ & $\begin{array}{c}0.06 \\
(0.24)\end{array}$ \\
\hline \multicolumn{5}{|l|}{ Tax Refund } \\
\hline Refund Amount (\$) & $\begin{array}{c}1,542 \\
(2,207)\end{array}$ & $\begin{array}{c}1,552 \\
(2,194)\end{array}$ & $\begin{array}{c}1,846 \\
(2,385)\end{array}$ & $\begin{array}{c}1,746 \\
(2,311)\end{array}$ \\
\hline Received EITC & $\begin{array}{c}0.35 \\
(0.48)\end{array}$ & $\begin{array}{c}0.35 \\
(0.48)\end{array}$ & $\begin{array}{c}0.35 \\
(0.48)\end{array}$ & $\begin{array}{c}0.31 \\
(0.46)\end{array}$ \\
\hline EITC Credit (If >0) & $\begin{array}{c}1,654 \\
(1,661)\end{array}$ & $\begin{array}{c}1,623 \\
(1,664)\end{array}$ & $\begin{array}{c}1,985 \\
(1,796)\end{array}$ & $\begin{array}{c}1,891 \\
(1,713)\end{array}$ \\
\hline EITC share & $\begin{array}{c}0.50 \\
(0.43)\end{array}$ & $\begin{array}{c}0.49 \\
(0.38)\end{array}$ & $\begin{array}{c}0.53 \\
(0.43)\end{array}$ & $\begin{array}{c}0.46 \\
(0.40)\end{array}$ \\
\hline \multicolumn{5}{|l|}{ Savings and Credit } \\
\hline Estimated Savings Balance & $\begin{array}{c}523 \\
(576)\end{array}$ & $\begin{array}{c}523 \\
(576)\end{array}$ & $\begin{array}{c}546 \\
(583)\end{array}$ & $\begin{array}{c}634 \\
(606)\end{array}$ \\
\hline FICO Score & $\begin{array}{l}666 \\
(87)\end{array}$ & $\begin{array}{l}666 \\
(88)\end{array}$ & $\begin{array}{l}675 \\
(89)\end{array}$ & $\begin{array}{l}684 \\
(80)\end{array}$ \\
\hline Credit Card Balances $(\$)$ & $\begin{array}{c}1,686 \\
(4,985)\end{array}$ & $\begin{array}{c}1,780 \\
(5,228)\end{array}$ & $\begin{array}{c}2,005 \\
(5,925)\end{array}$ & $\begin{array}{c}2,630 \\
(6,026)\end{array}$ \\
\hline $\begin{array}{l}\text { Observations } \\
\text { with Demographics }\end{array}$ & $\begin{array}{l}618 \\
548 \\
\end{array}$ & $\begin{array}{l}548 \\
548 \\
\end{array}$ & $\begin{array}{l}337 \\
303 \\
\end{array}$ & $\begin{array}{l}359 \\
319 \\
\end{array}$ \\
\hline
\end{tabular}

Note: The first column describes tax filers who completed the expectations survey. The remaining columns present similar descriptive statistics for individuals for whom we have additional information from the demographic survey (column 2), prior year tax return (column 3), or credit reports (column 4). All columns exclude individuals with subjective uncertainty (as measured by standard deviation of beliefs) in the top or bottom $1 \%$ of expectations survey respondents, or tax refund prediction errors in the top or bottom $1 \%$, as well as individuals with adjusted gross incomes below 0, as described in Section 2.4 of the text. Appendix Tables A1 and A2 present descriptive statistics for the full sample, including outlier observations. 
Table 2: Elicited Beliefs by Filer Group

\begin{tabular}{|c|c|c|c|c|c|c|c|c|c|}
\hline & \multirow[b]{2}{*}{ Core Sample } & \multicolumn{2}{|c|}{ Has Dependents } & \multicolumn{2}{|c|}{ Marital Status } & \multicolumn{2}{|c|}{ College Education } & \multicolumn{2}{|c|}{$\begin{array}{l}\text { Relative to } 2 \mathrm{x} \text { Federal Poverty } \\
\text { Line }\end{array}$} \\
\hline & & Yes & No & Married & Not Married & Yes & No & Below & Above \\
\hline & $(1)$ & $(2)$ & (3) & $(4)$ & $(5)$ & (6) & (7) & $(8)$ & $(9)$ \\
\hline \multicolumn{10}{|c|}{ Number of Bins with Positive Probability } \\
\hline $1 \mathrm{Bin}$ & $22.2 \%$ & $24.1 \%$ & $21.3 \%$ & $22.4 \%$ & $22.1 \%$ & $20.6 \%$ & $24.4 \%$ & $20.6 \%$ & $25.0 \%$ \\
\hline 2 Bins & $38.7 \%$ & $39.0 \%$ & $38.5 \%$ & $36.7 \%$ & $38.8 \%$ & $37.3 \%$ & $39.4 \%$ & $40.9 \%$ & $34.8 \%$ \\
\hline 3 Bins & $20.7 \%$ & $16.4 \%$ & $22.7 \%$ & $14.3 \%$ & $21.3 \%$ & $19.4 \%$ & $20.1 \%$ & $21.6 \%$ & $19.2 \%$ \\
\hline 4 Bins & $11.0 \%$ & $11.3 \%$ & $10.9 \%$ & $12.2 \%$ & $10.9 \%$ & $13.5 \%$ & $9.7 \%$ & $10.2 \%$ & $12.5 \%$ \\
\hline 5 Bins & $5.0 \%$ & $7.2 \%$ & $4.0 \%$ & $8.2 \%$ & $4.7 \%$ & $6.3 \%$ & $3.9 \%$ & $4.8 \%$ & $5.4 \%$ \\
\hline 6 Bins & $2.4 \%$ & $2.1 \%$ & $2.6 \%$ & $6.1 \%$ & $2.1 \%$ & $2.8 \%$ & $2.5 \%$ & $2.0 \%$ & $3.1 \%$ \\
\hline \multicolumn{10}{|l|}{ Qualitative Uncertainty } \\
\hline Very Certain & $34.0 \%$ & $30.3 \%$ & $35.7 \%$ & $44.9 \%$ & $33.0 \%$ & $32.5 \%$ & $37.3 \%$ & $36.5 \%$ & $29.5 \%$ \\
\hline Somewhat Certain & $41.7 \%$ & $48.2 \%$ & $38.8 \%$ & $36.7 \%$ & $42.2 \%$ & $38.9 \%$ & $42.7 \%$ & $40.6 \%$ & $43.8 \%$ \\
\hline Not Certain At All & $23.5 \%$ & $21.0 \%$ & $24.6 \%$ & $18.4 \%$ & $23.9 \%$ & $27.0 \%$ & $19.7 \%$ & $22.1 \%$ & $25.9 \%$ \\
\hline \multicolumn{10}{|l|}{ Quantitative Responses } \\
\hline Point Estimate & 1682 & 3520 & 837 & 2469 & 1614 & 1656 & 1726 & 1330 & 2303 \\
\hline \multicolumn{10}{|c|}{ Features of Parametric Distribution } \\
\hline Mean & 1605 & 3365 & 794 & 2378 & 1539 & 1614 & 1618 & 1251 & 2229 \\
\hline Std. Dev. & 426 & 769 & 268 & 648 & 407 & 448 & 413 & 353 & 553 \\
\hline Observations & 618 & 195 & 423 & 49 & 569 & 252 & 279 & 394 & 224 \\
\hline
\end{tabular}

Notes: This table reports responses to the beliefs survey. All statistics are means within each group. College education refers to any college experience regardless of degree attainment. The last panel contains statistics based on the parametric distributions fit to the probabilistic survey question described in Section 3. 
Table 3: Characteristics of Beliefs

\begin{tabular}{|c|c|c|c|c|c|}
\hline & \multirow[b]{2}{*}{$\begin{array}{c}\begin{array}{c}\text { Sample } \\
\text { Mean }\end{array} \\
(1) \\
\end{array}$} & \multicolumn{4}{|c|}{ Tax Circumstances and Beliefs } \\
\hline & & $\begin{array}{l}\text { S.D. of Elicited } \\
\text { Beliefs } \\
(2) \\
\end{array}$ & $\begin{array}{l}\text { Abs. Change in } \\
\text { Refund } \\
\text { (3) }\end{array}$ & $\begin{array}{l}\text { Abs. Change in } \\
\text { MTR } \\
(4) \\
\end{array}$ & $\begin{array}{c}\text { Abs. Forecast } \\
\text { Error } \\
(5)\end{array}$ \\
\hline Absolute Change in AGI & $\begin{array}{c}6.15 \\
(8.79)\end{array}$ & $\begin{array}{c}10.43 * * \\
(4.517)\end{array}$ & $\begin{array}{c}48.05 * * * \\
(10.83)\end{array}$ & $\begin{array}{c}0.00462 * * * \\
(0.00156)\end{array}$ & $\begin{array}{l}-0.481 \\
(6.413)\end{array}$ \\
\hline Has Dependents & $\begin{array}{c}0.32 \\
(0.00)\end{array}$ & $\begin{array}{c}478.5 * * * \\
(50.55)\end{array}$ & $\begin{array}{c}554.7 * * * \\
(142.4)\end{array}$ & $\begin{array}{c}0.0754 * * * \\
(0.0208)\end{array}$ & $\begin{array}{c}829.6 * * * \\
(106.7)\end{array}$ \\
\hline Change in No. Dependents & $\begin{array}{l}-0.04 \\
(0.55)\end{array}$ & $\begin{array}{l}-84.03 \\
(106.7)\end{array}$ & $\begin{array}{c}1660.1 * * * \\
(373.7)\end{array}$ & $\begin{array}{c}0.0586 \\
(0.0366)\end{array}$ & $\begin{array}{c}973.0 * * * \\
(338.4)\end{array}$ \\
\hline Married & $\begin{array}{c}0.08 \\
(0.00)\end{array}$ & $\begin{array}{l}176.8^{*} \\
(90.30)\end{array}$ & $\begin{array}{l}-143.2 \\
(244.8)\end{array}$ & $\begin{array}{l}-0.0446 \\
(0.0382)\end{array}$ & $\begin{array}{l}-41.38 \\
(158.1)\end{array}$ \\
\hline Change in Filing Status & $\begin{array}{c}0.09 \\
(0.29)\end{array}$ & $\begin{array}{l}-46.52 \\
(111.1)\end{array}$ & $\begin{array}{l}-64.57 \\
(415.3)\end{array}$ & $\begin{array}{c}0.0350 \\
(0.0428)\end{array}$ & $\begin{array}{l}-537.2 * \\
(301.1)\end{array}$ \\
\hline Received UI during Past Year & $\begin{array}{c}0.08 \\
(0.00)\end{array}$ & $\begin{array}{l}-16.94 \\
(66.57)\end{array}$ & $\begin{array}{l}-38.53 \\
(276.3)\end{array}$ & $\begin{array}{c}0.0199 \\
(0.0367)\end{array}$ & $\begin{array}{c}72.14 \\
(141.2)\end{array}$ \\
\hline Age 25 or Younger & $\begin{array}{c}0.22 \\
(0.42)\end{array}$ & $\begin{array}{l}-25.92 \\
(42.85)\end{array}$ & $\begin{array}{c}-331.4 * * \\
(156.2)\end{array}$ & $\begin{array}{l}0.00295 \\
(0.0176)\end{array}$ & $\begin{array}{l}-112.1 \\
(98.24)\end{array}$ \\
\hline Above Age 50 & $\begin{array}{c}0.28 \\
(0.45)\end{array}$ & $\begin{array}{c}-139.6 * * * \\
(38.26)\end{array}$ & $\begin{array}{c}-338.8 * * * \\
(126.3)\end{array}$ & $\begin{array}{l}-0.0217 \\
(0.0164)\end{array}$ & $\begin{array}{c}-196.4 * * \\
(92.50)\end{array}$ \\
\hline Any College & $\begin{array}{c}0.15 \\
(0.00)\end{array}$ & $\begin{array}{c}1.789 \\
(42.69)\end{array}$ & $\begin{array}{c}11.53 \\
(135.9)\end{array}$ & $\begin{array}{c}-0.000560 \\
(0.0163)\end{array}$ & $\begin{array}{c}122.9 \\
(87.52)\end{array}$ \\
\hline Female & $\begin{array}{c}0.62 \\
(0.49)\end{array}$ & $\begin{array}{l}-38.92 \\
(38.68)\end{array}$ & $\begin{array}{c}35.51 \\
(133.6)\end{array}$ & $\begin{array}{r}-0.00378 \\
(0.0172)\end{array}$ & $\begin{array}{l}-133.9 \\
(83.64)\end{array}$ \\
\hline Constant & --- & $\begin{array}{c}303.1 * * * \\
(48.92)\end{array}$ & $\begin{array}{c}374.5 * * * \\
(136.5)\end{array}$ & $\begin{array}{l}0.0310 * \\
(0.0177)\end{array}$ & $\begin{array}{c}672.2 * * * \\
(94.72)\end{array}$ \\
\hline $\begin{array}{l}\text { Observations } \\
\text { R-squared }\end{array}$ & $\begin{array}{c}618 \\
---\end{array}$ & $\begin{array}{c}618 \\
0.255\end{array}$ & $\begin{array}{c}337 \\
0.442\end{array}$ & $\begin{array}{c}337 \\
0.231\end{array}$ & $\begin{array}{c}618 \\
0.221\end{array}$ \\
\hline
\end{tabular}

Note: The first column describes the characteristics of filers in our core sample; these are the same as those in Table 1 but are included here for comparison. Columns 2-5 examine heterogeneity in filers' beliefs and tax situations, presenting estimates from regressions corresponding to equation 2 in the text. Each of these four columns shows estimates for the dependent variable indicated in the column header. The dependent variables are in dollar units; Absolute Change in AGI is in $\$ 1,000$ units. Absolute Forecast Error is the absolute difference between each filer's refund amount and their mean elicited belief. All specifications include the listed covariates, plus controls for whether a given demographic variable was missing. Tables A1 and A2 present additional descriptive statistics and Table A5 presents additional specifications. Robust standard errors are in parentheses. * $\mathrm{p}<0.10,{ }^{* *} \mathrm{p}<0.05, * * * \mathrm{p}<0.01$. 


\section{Table 4: Updating Rates}

\begin{tabular}{|c|c|c|c|c|}
\hline \multicolumn{5}{|c|}{ Dependent Variable: Difference between Mean Expectation and Last Year's Refund } \\
\hline & $\begin{array}{c}\text { No } \\
\text { Heterogeneity } \\
(1) \\
\end{array}$ & $\begin{array}{c}\text { Full } \\
\text { Heterogeneity } \\
(2) \\
\end{array}$ & $\begin{array}{c}\text { Tax } \\
\text { Determinants } \\
\text { Only } \\
(3) \\
\end{array}$ & $\begin{array}{c}\text { Demographics } \\
\text { Only } \\
(4) \\
\end{array}$ \\
\hline Change in Refund Amount over Last Year & $\begin{array}{c}0.597 * * * \\
(0.0722)\end{array}$ & $\begin{array}{c}0.233 \\
(0.149)\end{array}$ & $\begin{array}{c}0.264^{* *} \\
(0.122)\end{array}$ & $\begin{array}{c}0.580 * * * \\
(0.140)\end{array}$ \\
\hline \multicolumn{5}{|l|}{ Interacted with Change in Refund Amount } \\
\hline Absolute Change in AGI & & $\begin{array}{l}0.0118 * * \\
(0.00491)\end{array}$ & $\begin{array}{l}0.0113 * * \\
(0.00486)\end{array}$ & \\
\hline Absolute Change in MTR & & $\begin{array}{l}0.457^{*} \\
(0.246)\end{array}$ & $\begin{array}{l}0.476^{*} \\
(0.250)\end{array}$ & \\
\hline Has Dependents & & $\begin{array}{l}-0.180 \\
(0.160)\end{array}$ & $\begin{array}{r}-0.0277 \\
(0.144)\end{array}$ & \\
\hline Any Change in No. Dependents & & $\begin{array}{l}0.0127 \\
(0.144)\end{array}$ & $\begin{array}{l}0.0416 \\
(0.140)\end{array}$ & \\
\hline Married & & $\begin{array}{l}0.0305 \\
(0.153)\end{array}$ & $\begin{array}{r}-0.0174 \\
(0.173)\end{array}$ & \\
\hline Change in Filing Status & & $\begin{array}{c}0.184 \\
(0.146)\end{array}$ & $\begin{array}{c}0.194 \\
(0.153)\end{array}$ & \\
\hline Received UI during Past Year & & $\begin{array}{l}-0.316 \\
(0.225)\end{array}$ & $\begin{array}{l}-0.221 \\
(0.222)\end{array}$ & \\
\hline Age 25 or Younger & & $\begin{array}{l}-0.403 \\
(0.285)\end{array}$ & & $\begin{array}{c}-0.514^{* *} \\
(0.250)\end{array}$ \\
\hline Above Age 50 & & $\begin{array}{l}0.0207 \\
(0.115)\end{array}$ & & $\begin{array}{l}0.0133 \\
(0.177)\end{array}$ \\
\hline Any College & & $\begin{array}{c}0.112 \\
(0.131)\end{array}$ & & $\begin{array}{l}0.0231 \\
(0.152)\end{array}$ \\
\hline Female & & $\begin{array}{l}0.205^{*} \\
(0.119)\end{array}$ & & $\begin{array}{l}0.0469 \\
(0.158)\end{array}$ \\
\hline Observations & 337 & 337 & 337 & 337 \\
\hline R-squared & 0.336 & 0.411 & 0.395 & 0.348 \\
\hline No Updating (p-value) & $<.01$ & $<.01$ & $<.01$ & $<.01$ \\
\hline No Heterogeneity in Updating Rates (p-value) & $<.01$ & $<.01$ & $<.01$ & 0.31 \\
\hline Full Updating (p-value) & $<.01$ & $<.01$ & $<.01$ & $<.01$ \\
\hline
\end{tabular}

Notes: Estimated coefficients from equation 2 in the main text. Each control is interacted with the tax filer's change in refund amount. The sample includes all filers for whom tax refund information is available from the prior tax year. Specifications with demographic and economic controls (columns 2 -4) also control for missing value indicators for each variable; these coefficients are omitted for brevity. The last three rows present $\mathrm{p}$-values from $\mathrm{F}$-tests of the hypotheses of no updating $(\beta=0)$; no updating rate heterogeneity by filer characteristics; and complete updating $\left(X_{i}^{\prime} \beta=1 \forall i\right)$. Robust standard errors are in parentheses. ${ }^{*} \mathrm{p}<0.10,{ }^{* *} \mathrm{p}<0.05,{ }^{* * *} \mathrm{p}<0.01$. 
Table 5: Impact of Uncertainty on Borrowing

\begin{tabular}{|c|c|c|c|c|c|c|c|}
\hline & \multicolumn{4}{|c|}{ Baseline Model (OLS) } & \multicolumn{3}{|c|}{ 2SLS Estimates } \\
\hline & (1) & $(2)$ & $(3)$ & (4) & (5) & (6) & (7) \\
\hline & \multicolumn{7}{|c|}{ 2-Month Change in Balances } \\
\hline Expected Refund Amount & $\begin{array}{l}-39.94 \\
(27.59)\end{array}$ & $\begin{array}{c}-79.23 * * \\
(33.69)\end{array}$ & $\begin{array}{c}-44.23 \\
(38.21)\end{array}$ & $\begin{array}{c}-40.38 \\
(38.07)\end{array}$ & $\begin{array}{c}-271.7^{*} \\
(140.3)\end{array}$ & $\begin{array}{c}-199.4 \\
(131.0)\end{array}$ & $\begin{array}{c}-199.3 \\
(146.0)\end{array}$ \\
\hline Subjective Standard Deviation & & $\begin{array}{l}227.0 * \\
(135.0)\end{array}$ & $\begin{array}{l}237.2^{*} \\
(128.4)\end{array}$ & $\begin{array}{c}259.3 * * \\
(131.5)\end{array}$ & $\begin{array}{c}1339.1 * \\
(806.3)\end{array}$ & $\begin{array}{l}1194.6 \\
(769.9)\end{array}$ & $\begin{array}{l}1243.0 \\
(866.9)\end{array}$ \\
\hline & & & & & & First Stage & \\
\hline "Somewhat Sure" of Refund Amount & & & & & $\begin{array}{c}-0.154 * * \\
(0.0598)\end{array}$ & $\begin{array}{c}-0.154^{* *} \\
(0.0613)\end{array}$ & $\begin{array}{c}-0.140^{* *} \\
(0.0604)\end{array}$ \\
\hline "Very Sure" of Refund Amount & & & & & $\begin{array}{c}-0.185^{* * *} \\
(0.0598)\end{array}$ & $\begin{array}{c}-0.181 * * * \\
(0.0596)\end{array}$ & $\begin{array}{c}-0.156 * * * \\
(0.0586)\end{array}$ \\
\hline Controls & & & & & & & \\
\hline Demographics & & & $\mathrm{X}$ & $\mathrm{X}$ & & $\mathrm{X}$ & $\mathrm{X}$ \\
\hline Tax Determinants & & & & $\mathrm{X}$ & & & $\mathrm{X}$ \\
\hline First-stage F-stat & -- & -- & -- & -- & 4.89 & 4.73 & 3.67 \\
\hline Observations & 359 & 359 & 359 & 359 & 359 & 359 & 359 \\
\hline R-squared & 0.009 & 0.018 & 0.079 & 0.096 & -- & -- & -- \\
\hline
\end{tabular}

Note: This table investigates how uncertainty affects filers' borrowing behavior with regard to their tax refund. The regressions include all filers for whom we have expectations data and credit report data. The dependent variable is a 2-month change in non-installment debt balances, and coefficients are scaled to be per- $\$ 1000$ of the regressors. Columns 1-4 provide results from OLS regressions of the dependent variable on the expected refund amount and other covariates as listed. Columns 5-7 provide 2SLS estimates, where we use the qualitative uncertainty measures as instruments for subjective uncertainty. The demographic controls include controls for whether a filer is female, over 50, a college graduate, married, or has dependents. The tax determinants include controls for the (absolute value of the) change in AGI, a dummy for any change in the number of dependents, a dummy for a change in filing status, and a dummy for whether the filer received UI this year. Robust standard errors are in parentheses. ${ }^{*} \mathrm{p}<.1^{* *} \mathrm{p}<0.05 * * * \mathrm{p}<0.01$ 
Table 6: Robustness of Borrowing Results

\begin{tabular}{|c|c|c|c|c|c|c|c|c|c|}
\hline & \multirow[b]{2}{*}{$\begin{array}{c}\text { Baseline } \\
\text { (1) }\end{array}$} & \multicolumn{4}{|c|}{ Alternate Samples } & \multicolumn{4}{|c|}{ Additional Specifications } \\
\hline & & $\begin{array}{c}\text { No Direct } \\
\text { Deposit } \\
(2) \\
\end{array}$ & $\begin{array}{c}\text { No Savings } \\
(3) \\
\end{array}$ & $\begin{array}{c}\text { Can't Change } \\
\text { Income } \\
(4) \\
\end{array}$ & $\begin{array}{c}\text { No } \\
\text { Dependents } \\
(5)\end{array}$ & $\begin{array}{c}\text { Refund } \\
\text { Controls } \\
(6)\end{array}$ & $\begin{array}{c}\text { Income } \\
\text { Controls } \\
(7)\end{array}$ & $\begin{array}{c}\text { Refund \& } \\
\text { Income } \\
(8) \\
\end{array}$ & $\begin{array}{c}\text { Winsorize at } \\
1 \% \\
(9)\end{array}$ \\
\hline Expected Refund Amount & $\begin{array}{l}-40.38 \\
(38.07)\end{array}$ & $\begin{array}{l}-6.266 \\
(47.30)\end{array}$ & $\begin{array}{l}-35.28 \\
(79.27)\end{array}$ & $\begin{array}{l}-0.487 \\
(41.61)\end{array}$ & $\begin{array}{l}-70.50 \\
(68.33)\end{array}$ & $\begin{array}{c}17.86 \\
(39.15)\end{array}$ & $\begin{array}{l}-41.14 \\
(38.11)\end{array}$ & $\begin{array}{c}5.019 \\
(36.01)\end{array}$ & $\begin{array}{l}-9.558 \\
(76.60)\end{array}$ \\
\hline Subjective Standard Deviation & $\begin{array}{c}259.3 * * \\
(131.5)\end{array}$ & $\begin{array}{c}196.4 \\
(143.1)\end{array}$ & $\begin{array}{c}486.0 * * \\
(203.5)\end{array}$ & $\begin{array}{c}370.7 * * \\
(144.6)\end{array}$ & $\begin{array}{c}576.4 * * \\
(133.4)\end{array}$ & $\begin{array}{c}283.3 * * \\
(132.1)\end{array}$ & $\begin{array}{l}253.0 * \\
(131.7)\end{array}$ & $\begin{array}{l}252.4 * \\
(133.8)\end{array}$ & $\begin{array}{c}552.4 * * \\
(256.5)\end{array}$ \\
\hline $\begin{array}{r}\text { Demographics } \\
\text { Tax Determinants } \\
\text { Refund } \\
\text { Income }\end{array}$ & $\begin{array}{l}X \\
X\end{array}$ & $\begin{array}{l}X \\
X\end{array}$ & $\begin{array}{l}X \\
X\end{array}$ & $\begin{array}{l}X \\
X\end{array}$ & $\begin{array}{l}X \\
X\end{array}$ & $\begin{array}{c}X \\
X \\
\text { Linear }\end{array}$ & $\begin{array}{c}\mathrm{X} \\
\mathrm{X} \\
\text { Linear }\end{array}$ & $\begin{array}{c}X \\
X \\
\text { Cubic } \\
\text { Cubic }\end{array}$ & $\begin{array}{l}X \\
X\end{array}$ \\
\hline $\begin{array}{l}\text { Observations } \\
\text { R-squared }\end{array}$ & $\begin{array}{c}359 \\
0.096\end{array}$ & $\begin{array}{c}234 \\
0.103\end{array}$ & $\begin{array}{c}91 \\
0.273\end{array}$ & $\begin{array}{l}211 \\
0.13\end{array}$ & $\begin{array}{c}237 \\
0.107\end{array}$ & $\begin{array}{c}359 \\
0.112\end{array}$ & $\begin{array}{c}359 \\
0.097\end{array}$ & $\begin{array}{l}359 \\
0.12\end{array}$ & $\begin{array}{c}359 \\
0.073\end{array}$ \\
\hline
\end{tabular}

Note: This table investigates the robustness of the borrowing results in Table 5 . The regressions include all of the core sample tax filers for whom we have expectations data and credit report data. Column 1 repeats the main specification in Column 4 of Table 5. Columns $2-5$ present the same specification for different subsamples. The no direct deposit sample consists of filers who received their refund by mail, rather than direct deposit. The no savings sample consists of individuals who have less than $\$ 100$ in savings. The "can't change income" sample consists of individuals who, on the expectations survey, said that they could not easily change their income. Column 6-8 present results from regressions that contain additional controls for the size of refund received and for AGI. Column 9 repeats the main specification using a dependent variable that is winsorized at the $1 \%$ level (rather than $5 \%$ ). The demographic controls include controls for whether a filer is female, over 50, a college graduate, married, or has dependents. The tax determinants include controls for the (absolute value of the) change in AGI, a dummy for any change in the number of dependents, a dummy for a change in filing status, and a dummy for whether the filer received UI this year. Robust standard errors are in parentheses. ${ }^{*} \mathrm{p}<.1{ }^{* *} \mathrm{p}<0.05 * * * \mathrm{p}<0.01$ 
Table 7: Compensating Variation Under Different Utility Specifications

\begin{tabular}{|c|c|c|c|c|c|c|c|}
\hline & \multirow[b]{3}{*}{$\begin{array}{l}\text { Percent of } \\
\text { Sample } \\
(1)\end{array}$} & \multirow{2}{*}{\multicolumn{2}{|c|}{$\begin{array}{c}\text { Baseline Specification } \\
\text { CRRA, Gamma=3 }\end{array}$}} & \multicolumn{4}{|c|}{ Alternate Specifications, CRRA Utility } \\
\hline & & & & \multicolumn{2}{|c|}{ Gamma $=1$} & \multicolumn{2}{|c|}{ Gamma $=5$} \\
\hline & & $\begin{array}{c}\text { Uncertainty } \\
\text { (2) }\end{array}$ & $\begin{array}{c}\text { Uncertainty+ } \\
\text { Variability } \\
\text { (3) }\end{array}$ & $\begin{array}{c}\text { Uncertainty } \\
\text { (4) }\end{array}$ & $\begin{array}{c}\text { Uncertainty }+ \\
\text { Variability } \\
\text { (5) }\end{array}$ & $\begin{array}{c}\text { Uncertainty } \\
(6)\end{array}$ & $\begin{array}{c}\text { Uncertainty+ } \\
\text { Variability } \\
(7)\end{array}$ \\
\hline All Taxfilers & $100 \%$ & $\begin{array}{c}92.51 \\
{[11.75]} \\
(272.56)\end{array}$ & $\begin{array}{c}172.86 \\
{[24.49]} \\
(512.02)\end{array}$ & $\begin{array}{c}23.63 \\
{[3.82]} \\
(60.09)\end{array}$ & $\begin{array}{c}45.23 \\
{[8.72]} \\
(107.47)\end{array}$ & $\begin{array}{c}127.83 \\
{[20.05]} \\
(316.78)\end{array}$ & $\begin{array}{c}265.68 \\
{[40.18]} \\
(698.82)\end{array}$ \\
\hline High School or Less & $45 \%$ & $\begin{array}{c}85.71 \\
{[12.48]} \\
(240.53)\end{array}$ & $\begin{array}{l}155.95 \\
{[24.88]} \\
(419.53)\end{array}$ & $\begin{array}{l}24.31 \\
{[4.02]} \\
(64.52)\end{array}$ & $\begin{array}{c}45.84 \\
{[8.54]} \\
(113.37)\end{array}$ & $\begin{array}{l}119.83 \\
{[21.26]} \\
(289.53)\end{array}$ & $\begin{array}{l}244.20 \\
{[42.29]} \\
(609.74)\end{array}$ \\
\hline No Status Changes & $47 \%$ & $\begin{array}{c}95.40 \\
{[10.90]} \\
(326.91)\end{array}$ & $\begin{array}{l}167.61 \\
{[23.20]} \\
(571.03)\end{array}$ & $\begin{array}{l}21.88 \\
{[3.54]} \\
(58.02)\end{array}$ & $\begin{array}{c}41.99 \\
{[8.54]} \\
(103.31)\end{array}$ & $\begin{array}{l}131.19 \\
{[18.36]} \\
(362.11)\end{array}$ & $\begin{array}{l}261.56 \\
{[37.57]} \\
(781.35)\end{array}$ \\
\hline Female & $52 \%$ & $\begin{array}{c}92.31 \\
{[15.27]} \\
(248.74)\end{array}$ & $\begin{array}{c}178.20 \\
{[30.92]} \\
(488.31)\end{array}$ & $\begin{array}{c}26.26 \\
{[4.95]} \\
(65.78)\end{array}$ & $\begin{array}{c}49.83 \\
{[11.42]} \\
(116.41)\end{array}$ & $\begin{array}{c}130.72 \\
{[26.16]} \\
(310.14)\end{array}$ & $\begin{array}{c}273.23 \\
{[51.41]} \\
(680.51)\end{array}$ \\
\hline Below 2xFederal Poverty Line & $64 \%$ & $\begin{array}{l}108.48 \\
{[12.62]} \\
(308.52)\end{array}$ & $\begin{array}{l}204.40 \\
{[25.39]} \\
(595.48)\end{array}$ & $\begin{array}{l}27.12 \\
{[4.04]} \\
(68.09)\end{array}$ & $\begin{array}{c}50.33 \\
{[8.52]} \\
(120.24)\end{array}$ & $\begin{array}{l}134.43 \\
{[21.93]} \\
(307.04)\end{array}$ & $\begin{array}{l}297.78 \\
{[42.41]} \\
(761.99)\end{array}$ \\
\hline EITC Filer & $35 \%$ & $\begin{array}{c}164.83 \\
{[33.18]} \\
(368.15)\end{array}$ & $\begin{array}{c}310.01 \\
{[65.68]} \\
(710.33)\end{array}$ & $\begin{array}{c}42.31 \\
{[10.43]} \\
(85.00)\end{array}$ & $\begin{array}{c}79.46 \\
{[22.49]} \\
(151.83)\end{array}$ & $\begin{array}{c}223.35 \\
{[57.79]} \\
(430.98)\end{array}$ & $\begin{array}{c}462.92 \\
{[111.37]} \\
(934.17)\end{array}$ \\
\hline High Uncertainty Filer & $50 \%$ & $\begin{array}{c}178.89 \\
{[46.49]} \\
(365.73)\end{array}$ & $\begin{array}{c}333.73 \\
{[90.01]} \\
(687.74)\end{array}$ & $\begin{array}{c}45.27 \\
{[14.25]} \\
(79.26)\end{array}$ & $\begin{array}{c}85.80 \\
{[29.85]} \\
(140.61)\end{array}$ & $\begin{array}{l}244.50 \\
{[72.49]} \\
(416.35)\end{array}$ & $\begin{array}{c}510.19 \\
{[156.33]} \\
(925.89)\end{array}$ \\
\hline
\end{tabular}

Note: This table shows the mean compensating variation for different demographic groups under two scenarios. Under the "uncertainty" scenario, individuals are given per-period transfers such that they are as well off as they are when they choose debt and consumption levels, knowing their future refund. Under the "uncertainty + variability" scenario, individuals are given per-period transfers such that they are as well off as they are when they face a deterministic refund equal to the expected refund. High Uncertainty is defined as having above-median subjective standard deviation, and No Status Changes refers to having the same filing status and number of dependents as in the preceding tax year The columns specify different assumptions on individuals' utility functions. Medians are in brackets. More information on how we compute CV is provided in Section 5.2. 


\section{A For Online Publication: Appendix Tables and Figures}

Figure A1: Tax Site Client Flow

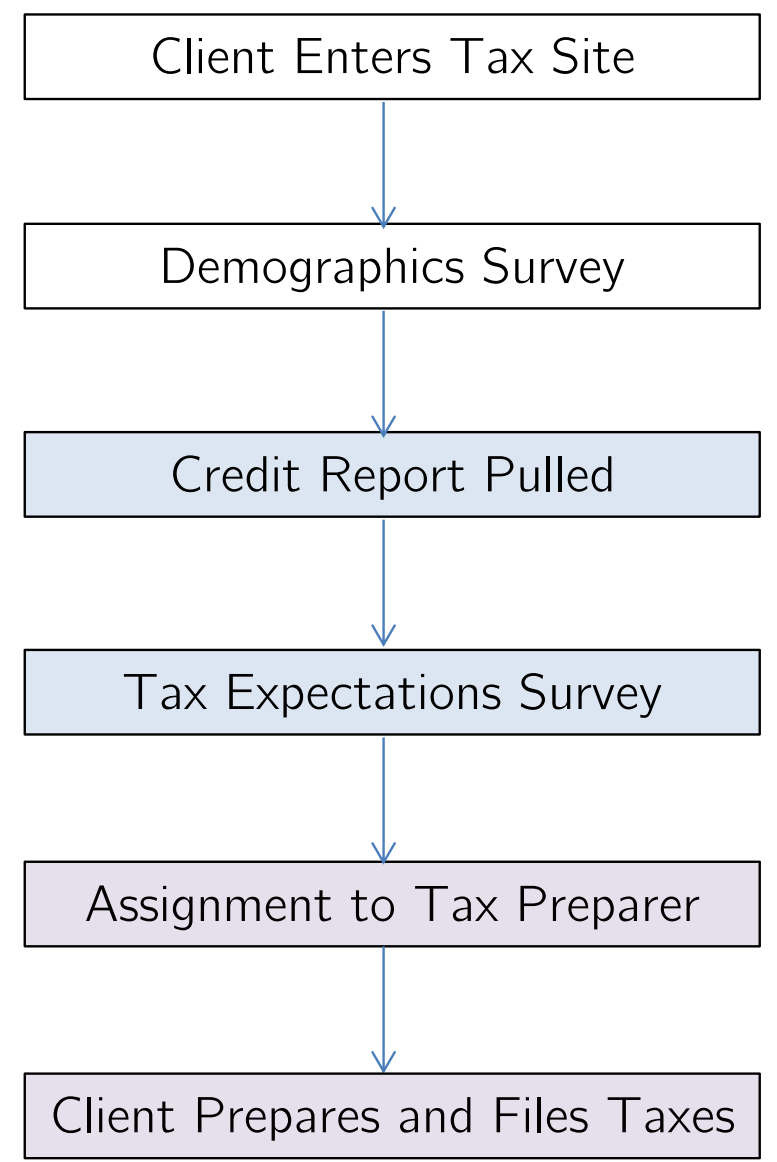

Note: This figure shows the steps a tax filer would go through upon arriving at the center. The steps in white occur before a filer has met with a financial guide or tax preparer. The steps in blue are completed in collaboration with one of the site's financial guides. Filers provided consent for their tax, credit, and survey information to be used for research purposes immediately prior to the tax expectations survey. The steps in purple are completed with the help of a volunteer tax preparer. 


\section{Figure A2: Fitting Beliefs to Normal Distributions}
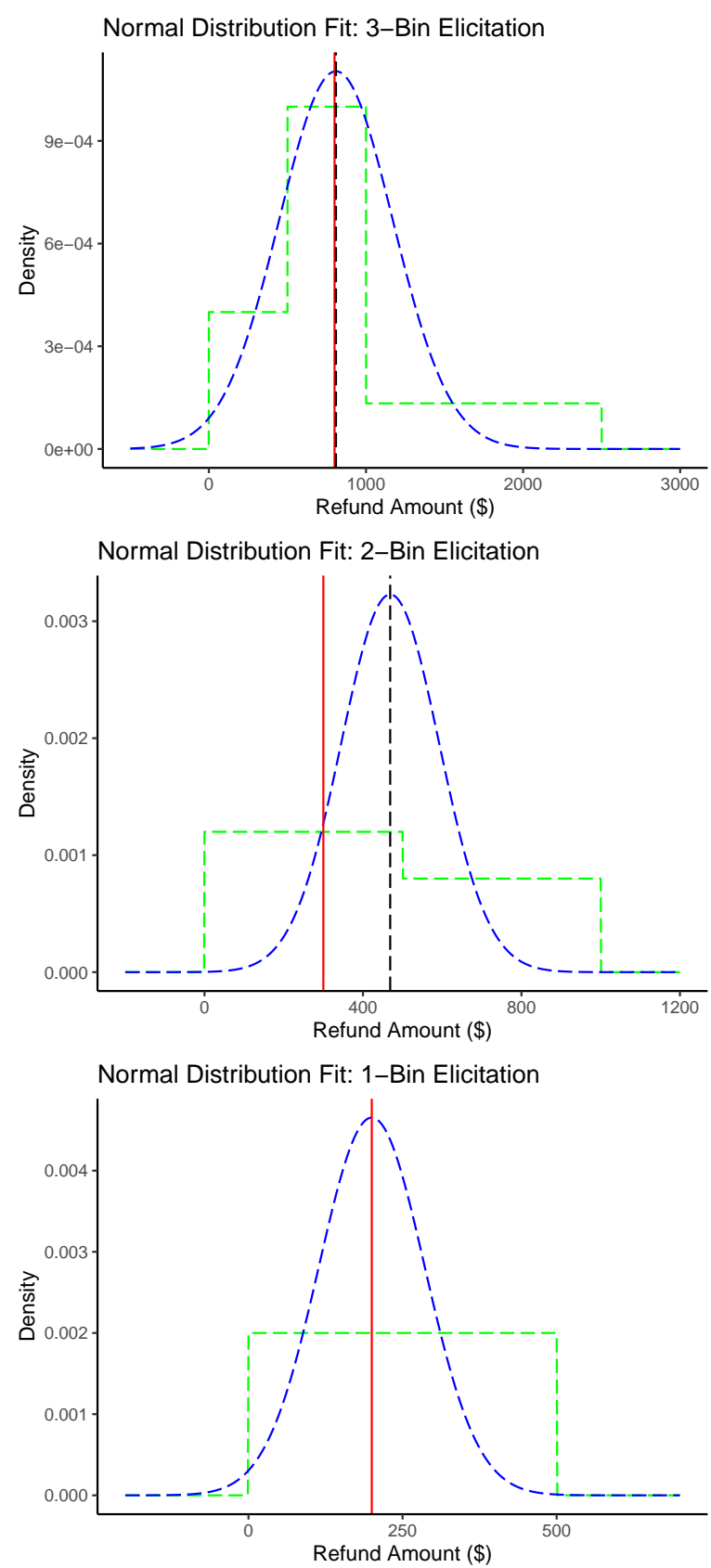

Note: This figure shows how we fit probabilistic beliefs to normal distributions if the individual places positive mass in 3 or more bins (top), in 2 bins (middle) or 1 bin (bottom). Solid lines denote data; dashed lines denote fitted distributions. The green dashed lines report the distribution of beliefs, assigning a uniform density over the density in each bin. The red line denotes the point estimate. The dashed blue curves show the density of the fitted distribution and the dashed black line shows the mean of this distribution. More information on how we fit beliefs to normal distributions is provided in Section 3. Graphs describing how we fit beliefs to beta distributions are provided in Figure A6. Table 2 presents descriptive statistics on the fitted beliefs. 
Figure A3: Expectation Outliers and Core Sample

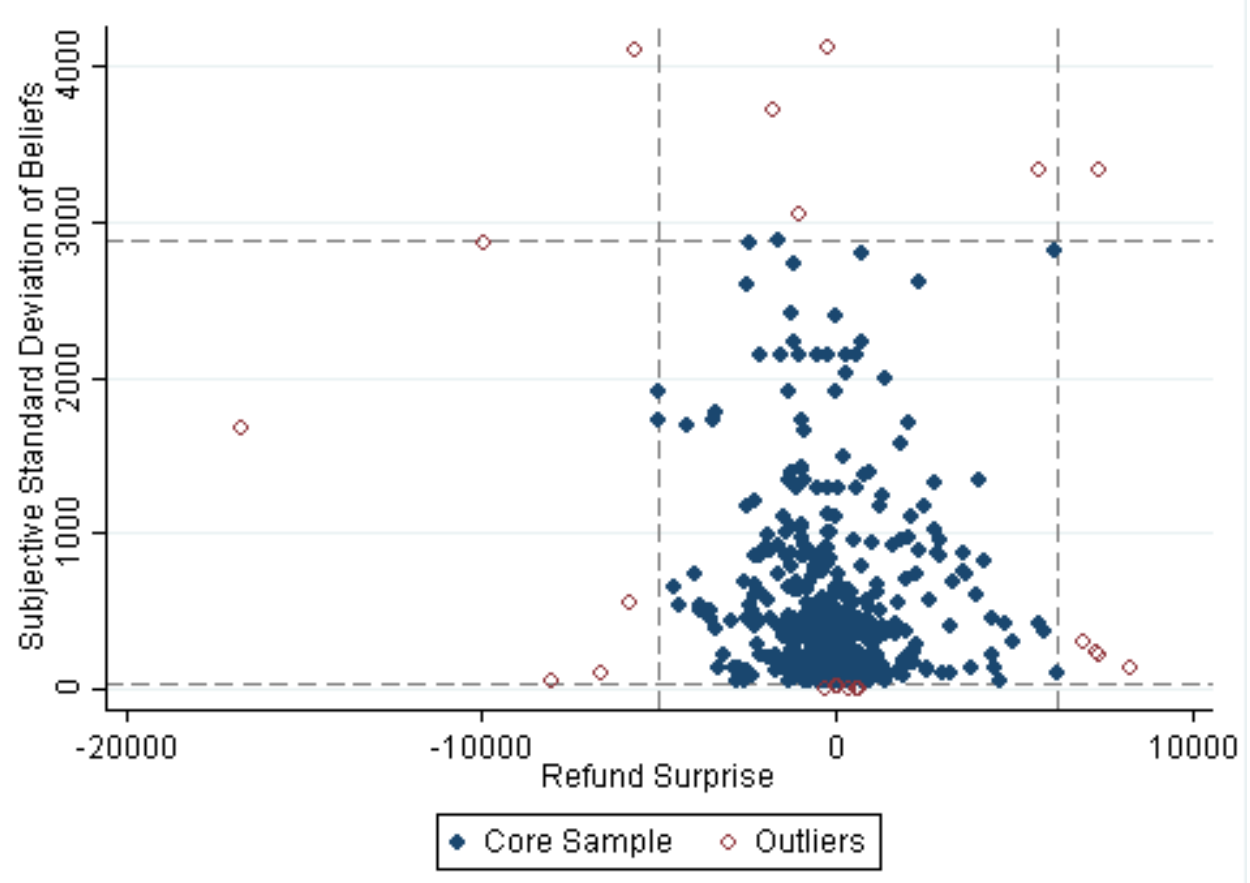

Note: This figure plots the fitted standard deviation of subjective beliefs about refund size, against the realized refund prediction errors. Dotted lines denote the thresholds at which the top and bottom $1 \%$ of refund prediction errors and the top and bottom $1 \%$ of subjective standard deviations are excluded as outliers. Solid diamonds represent the core sample excluding outliers and hollow diamonds represent the outliers. See Tables 1, A1, and A2 for summary statistics on these two groups. 
Figure A4: Refund Uncertainty and Borrowing Behavior

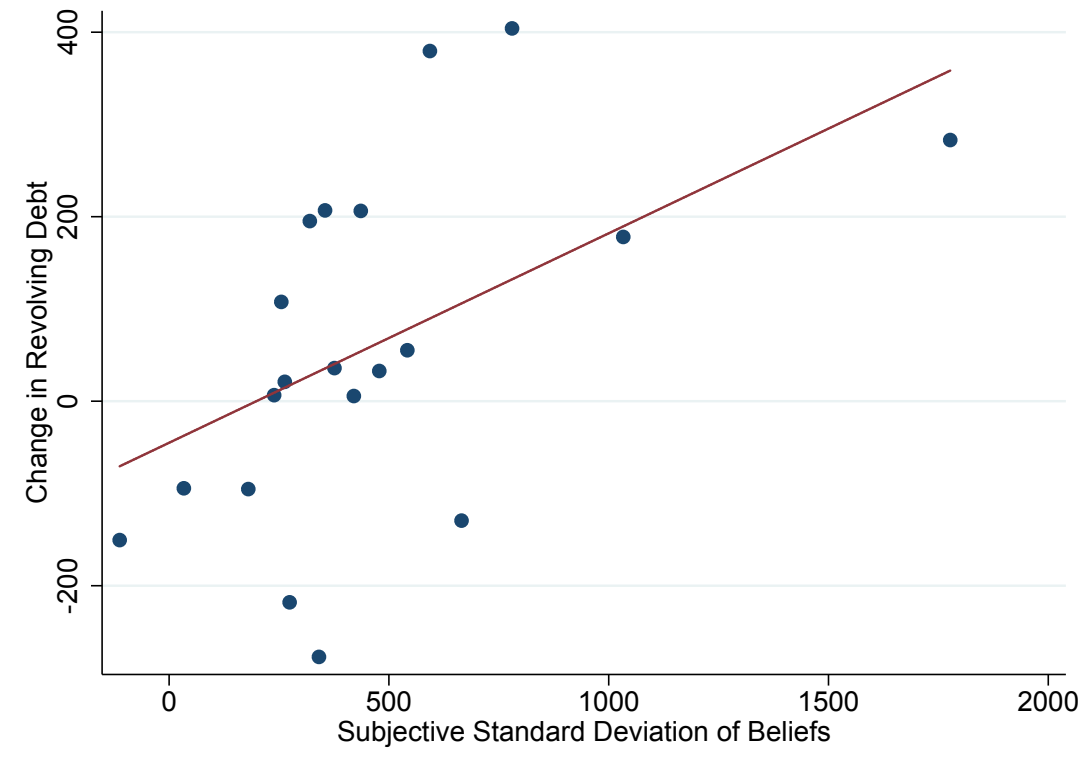

Note: This figure shows a binned scatterplot of 2-month changes in non-installment balances against subjective uncertainty corresponding to the regression specification in equation 4 . These data are plotted after partialling out the demographic and tax filer characteristics included in column 4 of Table 5. 
Table A1: Descriptive Statistics

\begin{tabular}{|c|c|c|c|c|c|}
\hline & \multirow[b]{2}{*}{$\begin{array}{c}\text { Core Sample } \\
\text { Tax Data \& } \\
\text { Expectations } \\
\text { Data } \\
\text { (1) } \\
\end{array}$} & \multicolumn{4}{|c|}{ All Filers } \\
\hline & & $\begin{array}{c}\text { Tax Data \& } \\
\text { Expectations } \\
\text { Data } \\
(2) \\
\end{array}$ & $\begin{array}{c}\text { Tax Data, } \\
\text { Expectations } \\
\text { Data, \& } \\
\text { Demographics } \\
\text { (3) }\end{array}$ & $\begin{array}{c}\text { Current and } \\
\text { Prior Tax Data } \\
\text { \& Expectations } \\
\text { Data } \\
(4) \\
\end{array}$ & $\begin{array}{c}\text { Tax Data, } \\
\text { Expectations } \\
\text { Data, \& Credit } \\
\text { Data } \\
(5)\end{array}$ \\
\hline \multicolumn{6}{|l|}{ Demographic Characteristics } \\
\hline Female & $\begin{array}{c}0.62 \\
(0.15)\end{array}$ & $\begin{array}{c}0.62 \\
(0.15)\end{array}$ & $\begin{array}{c}0.62 \\
(0.15)\end{array}$ & $\begin{array}{c}0.65 \\
(0.17)\end{array}$ & $\begin{array}{c}0.68 \\
(0.20)\end{array}$ \\
\hline Age & $\begin{array}{c}40.21 \\
(15.92)\end{array}$ & $\begin{array}{c}40.46 \\
(15.90)\end{array}$ & $\begin{array}{c}40.29 \\
(15.78)\end{array}$ & $\begin{array}{c}42.82 \\
(15.76)\end{array}$ & $\begin{array}{c}41.79 \\
(15.96)\end{array}$ \\
\hline High School or Above & $\begin{array}{c}0.82 \\
(0.38)\end{array}$ & $\begin{array}{c}0.82 \\
(0.39)\end{array}$ & $\begin{array}{c}0.82 \\
(0.39)\end{array}$ & $\begin{array}{c}0.84 \\
(0.37)\end{array}$ & $\begin{array}{c}0.85 \\
(0.36)\end{array}$ \\
\hline BA Degree & $\begin{array}{c}0.15 \\
(0.36)\end{array}$ & $\begin{array}{c}0.15 \\
(0.36)\end{array}$ & $\begin{array}{c}0.15 \\
(0.36)\end{array}$ & $\begin{array}{c}0.17 \\
(0.38)\end{array}$ & $\begin{array}{c}0.20 \\
(0.40)\end{array}$ \\
\hline \multicolumn{6}{|c|}{ Economic and Tax Characteristics } \\
\hline Adjusted Gross Income (\$) & $\begin{array}{c}20,637 \\
(15,930)\end{array}$ & $\begin{array}{c}20,998 \\
(15,941)\end{array}$ & $\begin{array}{c}21,041 \\
(15,777)\end{array}$ & $\begin{array}{c}23,844 \\
(16,126)\end{array}$ & $\begin{array}{c}24,311 \\
(16,190)\end{array}$ \\
\hline Has Dependents & $\begin{array}{c}0.32 \\
(0.47)\end{array}$ & $\begin{array}{c}0.32 \\
(0.47)\end{array}$ & $\begin{array}{c}0.32 \\
(0.47)\end{array}$ & $\begin{array}{c}0.36 \\
(0.48)\end{array}$ & $\begin{array}{c}0.35 \\
(0.48)\end{array}$ \\
\hline Married & $\begin{array}{c}0.08 \\
(0.27)\end{array}$ & $\begin{array}{c}0.08 \\
(0.28)\end{array}$ & $\begin{array}{c}0.07 \\
(0.26)\end{array}$ & $\begin{array}{c}0.07 \\
(0.25)\end{array}$ & $\begin{array}{c}0.08 \\
(0.28)\end{array}$ \\
\hline Single Head of Household & $\begin{array}{c}0.27 \\
(0.44)\end{array}$ & $\begin{array}{c}0.27 \\
(0.45)\end{array}$ & $\begin{array}{c}0.28 \\
(0.45)\end{array}$ & $\begin{array}{c}0.31 \\
(0.46)\end{array}$ & $\begin{array}{c}0.30 \\
(0.46)\end{array}$ \\
\hline Filed Schedule C & $\begin{array}{c}0.08 \\
(0.27)\end{array}$ & $\begin{array}{c}0.07 \\
(0.26)\end{array}$ & $\begin{array}{c}0.07 \\
(0.26)\end{array}$ & $\begin{array}{c}0.06 \\
(0.24)\end{array}$ & $\begin{array}{c}0.07 \\
(0.26)\end{array}$ \\
\hline Lost Job & $\begin{array}{c}0.08 \\
(0.27)\end{array}$ & $\begin{array}{c}0.08 \\
(0.26)\end{array}$ & $\begin{array}{c}0.07 \\
(0.26)\end{array}$ & $\begin{array}{c}0.07 \\
(0.25)\end{array}$ & $\begin{array}{c}0.06 \\
(0.23)\end{array}$ \\
\hline \multicolumn{6}{|l|}{ Tax Refund } \\
\hline Refund Amount (\$) & $\begin{array}{c}1,542 \\
(2,207)\end{array}$ & $\begin{array}{c}1,585 \\
(2,372)\end{array}$ & $\begin{array}{c}1,605 \\
(2,383)\end{array}$ & $\begin{array}{c}1,867 \\
(2,511)\end{array}$ & $\begin{array}{c}1,745 \\
(2,508)\end{array}$ \\
\hline Received EITC & $\begin{array}{c}0.35 \\
(0.48)\end{array}$ & $\begin{array}{c}0.35 \\
(0.48)\end{array}$ & $\begin{array}{c}0.35 \\
(0.48)\end{array}$ & $\begin{array}{c}0.35 \\
(0.48)\end{array}$ & $\begin{array}{c}0.31 \\
(0.46)\end{array}$ \\
\hline EITC Credit (If $>0$ ) & $\begin{array}{c}1,654 \\
(1,661)\end{array}$ & $\begin{array}{c}1,730 \\
(1,703)\end{array}$ & $\begin{array}{c}1,723 \\
(1,717)\end{array}$ & $\begin{array}{c}2,008 \\
(1,796)\end{array}$ & $\begin{array}{c}1,957 \\
(1,746)\end{array}$ \\
\hline EITC share & $\begin{array}{c}0.50 \\
(0.43)\end{array}$ & $\begin{array}{c}0.50 \\
(0.42)\end{array}$ & $\begin{array}{c}0.49 \\
(0.37)\end{array}$ & $\begin{array}{c}0.53 \\
(0.41)\end{array}$ & $\begin{array}{c}0.46 \\
(0.38)\end{array}$ \\
\hline Chose Direct Deposit & $\begin{array}{c}0.59 \\
(0.49)\end{array}$ & $\begin{array}{c}0.58 \\
(0.49)\end{array}$ & $\begin{array}{c}0.58 \\
(0.49)\end{array}$ & $\begin{array}{c}0.63 \\
(0.48)\end{array}$ & $\begin{array}{c}0.65 \\
(0.48)\end{array}$ \\
\hline $\begin{array}{l}\text { Observations } \\
\text { with Demographics }\end{array}$ & $\begin{array}{l}618 \\
548\end{array}$ & $\begin{array}{l}692 \\
616\end{array}$ & $\begin{array}{l}616 \\
616\end{array}$ & $\begin{array}{l}375 \\
339\end{array}$ & $\begin{array}{l}400 \\
357\end{array}$ \\
\hline
\end{tabular}

Note: This table provides descriptive statistics on our sample of low-income filers. The first column describes our core sample, as shown previously in Table 1. The remaining columns show samples analogous to those shown in Table 1, here including outlier observations. These are individuals with subjective uncertainty in the top or bottom $1 \%$ of expectations survey respondents, or tax refund prediction errors in the top or bottom $1 \%$, as well as individuals with adjusted gross incomes below 0 . Additional descriptive statistics are provided in Table A2. 
Table A2: Descriptive Statistics

\begin{tabular}{|c|c|c|c|c|c|}
\hline & \multirow[b]{2}{*}{$\begin{array}{c}\text { Core Sample } \\
\text { Tax Data \& } \\
\text { Expectations } \\
\text { Data } \\
(1) \\
\end{array}$} & \multicolumn{4}{|c|}{ All Filers } \\
\hline & & $\begin{array}{c}\text { Tax Data \& } \\
\text { Expectations } \\
\text { Data } \\
(2) \\
\end{array}$ & $\begin{array}{c}\text { Tax Data, } \\
\text { Expectations } \\
\text { Data, \& } \\
\text { Demographics } \\
\text { (3) }\end{array}$ & $\begin{array}{c}\text { Current and } \\
\text { Prior Tax Data } \\
\text { \& Expectations } \\
\text { Data } \\
(4) \\
\end{array}$ & $\begin{array}{c}\text { Tax Data, } \\
\text { Expectations } \\
\text { Data, \& Credit } \\
\text { Data } \\
(5)\end{array}$ \\
\hline \multicolumn{6}{|l|}{ Savings and Credit } \\
\hline Estimated Savings Balance & $\begin{array}{c}523 \\
(576)\end{array}$ & $\begin{array}{c}522 \\
(572)\end{array}$ & $\begin{array}{c}522 \\
(572)\end{array}$ & $\begin{array}{c}543 \\
(580)\end{array}$ & $\begin{array}{c}627 \\
(603)\end{array}$ \\
\hline FICO Score & $\begin{array}{l}666 \\
(87)\end{array}$ & $\begin{array}{l}664 \\
(86)\end{array}$ & $\begin{array}{l}663 \\
(86)\end{array}$ & $\begin{array}{l}672 \\
(87)\end{array}$ & $\begin{array}{l}682 \\
(80)\end{array}$ \\
\hline Credit Card Balances $(\$)$ & $\begin{array}{c}1,686 \\
(4,985)\end{array}$ & $\begin{array}{c}1,680 \\
(4,836)\end{array}$ & $\begin{array}{c}1,749 \\
(5,029)\end{array}$ & $\begin{array}{c}1,954 \\
(5,698)\end{array}$ & $\begin{array}{c}2,638 \\
(5,850)\end{array}$ \\
\hline Non-Mortgage Installment Balances & $\begin{array}{c}9,612 \\
(23,488)\end{array}$ & $\begin{array}{c}9,359 \\
(22,694)\end{array}$ & $\begin{array}{c}9,632 \\
(23,438)\end{array}$ & $\begin{array}{c}11,394 \\
(25,964)\end{array}$ & $\begin{array}{c}12,348 \\
(26,223)\end{array}$ \\
\hline Has Mortgage & $\begin{array}{c}0.04 \\
(0.21)\end{array}$ & $\begin{array}{c}0.05 \\
(0.21)\end{array}$ & $\begin{array}{c}0.05 \\
(0.22)\end{array}$ & $\begin{array}{c}0.06 \\
(0.24)\end{array}$ & $\begin{array}{c}0.06 \\
(0.23)\end{array}$ \\
\hline \multicolumn{6}{|l|}{ Filing Characterisstics } \\
\hline Absolute Change in AGI & $\begin{array}{c}6.15 \\
(8.79)\end{array}$ & $\begin{array}{c}6.27 \\
(9.01)\end{array}$ & $\begin{array}{c}6.17 \\
(8.79)\end{array}$ & $\begin{array}{c}6.24 \\
(9.01)\end{array}$ & $\begin{array}{c}6.21 \\
(9.59)\end{array}$ \\
\hline Change in Filling Status & $\begin{array}{c}0.09 \\
(0.29)\end{array}$ & $\begin{array}{c}0.10 \\
(0.30)\end{array}$ & $\begin{array}{c}0.10 \\
(0.30)\end{array}$ & $\begin{array}{c}0.10 \\
(0.30)\end{array}$ & $\begin{array}{c}0.07 \\
(0.26)\end{array}$ \\
\hline Received UI during Past Year & $\begin{array}{c}0.08 \\
(0.27)\end{array}$ & $\begin{array}{c}0.08 \\
(0.26)\end{array}$ & $\begin{array}{c}0.07 \\
(0.26)\end{array}$ & $\begin{array}{c}0.07 \\
(0.25)\end{array}$ & $\begin{array}{c}0.06 \\
(0.23)\end{array}$ \\
\hline Change in Number of Dependents & $\begin{array}{l}-0.04 \\
(0.55)\end{array}$ & $\begin{array}{l}-0.04 \\
(0.57)\end{array}$ & $\begin{array}{l}-0.04 \\
(0.59)\end{array}$ & $\begin{array}{l}-0.04 \\
(0.57)\end{array}$ & $\begin{array}{l}-0.04 \\
(0.54)\end{array}$ \\
\hline Any Change in Number of Dependents & $\begin{array}{c}0.13 \\
(0.33)\end{array}$ & $\begin{array}{c}0.13 \\
(0.34)\end{array}$ & $\begin{array}{c}0.14 \\
(0.35)\end{array}$ & $\begin{array}{c}0.13 \\
(0.34)\end{array}$ & $\begin{array}{c}0.10 \\
(0.30)\end{array}$ \\
\hline $\begin{array}{l}\text { Observations } \\
\text { with Demographics }\end{array}$ & $\begin{array}{l}618 \\
548\end{array}$ & $\begin{array}{l}692 \\
616\end{array}$ & $\begin{array}{l}616 \\
616\end{array}$ & $\begin{array}{l}375 \\
339\end{array}$ & $\begin{array}{l}400 \\
357\end{array}$ \\
\hline
\end{tabular}

Note: This table provides descriptive statistics on our sample of low-income filers. The first column describes our core sample, as shown previously in Table 1. The remaining columns show samples analogous to those shown in Table 1 , here including outlier observations. These are individuals with subjective uncertainty in the top or bottom $1 \%$ of expectations survey respondents, or tax refund prediction errors in the top or bottom $1 \%$, as well as individuals with adjusted gross incomes below 0 . Additional descriptive statistics are provided in Table A1. 
Table A3: Parametric Belief Distributions

\begin{tabular}{|c|c|c|c|c|c|c|c|c|}
\hline & \multicolumn{4}{|c|}{ Normal Distribution } & \multicolumn{4}{|c|}{ Beta Distribution } \\
\hline & $\begin{array}{c}\text { Baseline } \\
(1)\end{array}$ & $\begin{array}{c}\text { Exclude } \\
50 / 50 \\
(2) \\
\end{array}$ & $\begin{array}{c}\text { Exclude } \\
\text { Single Bins } \\
(3)\end{array}$ & $\begin{array}{l}\text { All } \\
(4) \\
\end{array}$ & $\begin{array}{c}\text { Baseline } \\
(5)\end{array}$ & $\begin{array}{c}\text { Exclude } \\
50 / 50 \\
(6) \\
\end{array}$ & $\begin{array}{c}\text { Exclude } \\
\text { Single Bins } \\
(7)\end{array}$ & $\begin{array}{l}\text { All } \\
(8)\end{array}$ \\
\hline Mean & $\begin{array}{c}1,605 \\
(2000)\end{array}$ & $\begin{array}{c}1,641 \\
(2061)\end{array}$ & $\begin{array}{c}1,322 \\
(1407)\end{array}$ & $\begin{array}{c}1,678 \\
(2187)\end{array}$ & $\begin{array}{c}1,837 \\
(2584)\end{array}$ & $\begin{array}{c}1,905 \\
(2698)\end{array}$ & $\begin{array}{c}1,435 \\
(1705)\end{array}$ & $\begin{array}{l}1,932 \\
(2796)\end{array}$ \\
\hline Median & $\begin{array}{c}1,605 \\
(2000)\end{array}$ & $\begin{array}{c}1,641 \\
(2061)\end{array}$ & $\begin{array}{c}1,322 \\
(1407)\end{array}$ & $\begin{array}{c}1,678 \\
(2187)\end{array}$ & $\begin{array}{c}1,943 \\
(3138)\end{array}$ & $\begin{array}{c}2,026 \\
(3299)\end{array}$ & $\begin{array}{c}1,582 \\
(2626)\end{array}$ & $\begin{array}{l}2,068 \\
(3407)\end{array}$ \\
\hline Std. Dev. & $\begin{array}{c}426 \\
(510)\end{array}$ & $\begin{array}{c}457 \\
(535)\end{array}$ & $\begin{array}{c}385 \\
(456)\end{array}$ & $\begin{array}{c}454 \\
(599)\end{array}$ & $\begin{array}{c}690 \\
(895)\end{array}$ & $\begin{array}{c}739 \\
(941)\end{array}$ & $\begin{array}{c}578 \\
(725)\end{array}$ & $\begin{array}{c}733 \\
(1005)\end{array}$ \\
\hline Observations & 618 & 541 & 584 & 647 & 618 & 541 & 584 & 647 \\
\hline
\end{tabular}

Notes: This table reports features of parametric belief distributions under alternative assumptions. Statistics are aggregated across all tax filers in the main analysis sample. The first set of four columns contains statistics based on the normal distributions fit to the probabilistic survey question described in Section 3. The second set of columns contain statistics based on beta distributions. We describe how we fit these distributions in Section 3 and Appendix E. The first column in each set presents our baseline sample. The second column excludes individuals who put 50/50 probability on two bins. The third column excludes individuals who put $100 \%$ probability on a single bin. The final column includes all tax filers who filled out the expectations survey; the sample size in this column differs from that in Table A1, column 2, because parametric belief distributions are only available for individuals in the full sample who reported internally consistent beliefs, as described in footnote 7 of the text. 
Table A4: Features of Subjective Belief Distributions

\begin{tabular}{|c|c|c|c|c|c|c|}
\hline & $\begin{array}{l}\text { Mean } \\
\text { (1) }\end{array}$ & $\begin{array}{c}\text { Standard } \\
\text { Deviation } \\
\text { (2) }\end{array}$ & $\begin{array}{c}25 \text { th } \\
\text { Percentile } \\
(3)\end{array}$ & $\begin{array}{c}50 \text { th } \\
\text { Percentile } \\
(4)\end{array}$ & $\begin{array}{c}75 \text { th } \\
\text { Percentile } \\
(5)\end{array}$ & $\begin{array}{c}\text { Sample Size } \\
(6)\end{array}$ \\
\hline \multicolumn{7}{|l|}{ Qualitative Uncertainty } \\
\hline Very Sure & $34 \%$ & $47 \%$ & & & & 618 \\
\hline Somewhat Sure & $42 \%$ & $49 \%$ & & & & 618 \\
\hline Not Sure & $23 \%$ & $42 \%$ & & & & 618 \\
\hline Point Forecast & 1,682 & 2,115 & 400 & 1,000 & 2,000 & 616 \\
\hline \multicolumn{7}{|c|}{ Moments of Belief Distribution } \\
\hline Mean & $1,605.35$ & $2,000.49$ & 441.78 & 900.00 & $1,930.96$ & 618 \\
\hline Standard Deviation & 425.87 & 509.73 & 117.60 & 217.68 & 494.43 & 618 \\
\hline Coefficient of Variation & 131.25 & $1,264.63$ & 0.14 & 0.27 & 0.51 & 606 \\
\hline \multicolumn{7}{|c|}{ Moments as a Fraction of Income } \\
\hline Mean & 0.16 & 0.65 & 0.03 & 0.06 & 0.15 & 613 \\
\hline Standard Deviation & 0.07 & 0.37 & 0.01 & 0.02 & 0.04 & 613 \\
\hline Change in Refund & $-\$ 92$ & $\$ 1,625$ & $-\$ 491$ & $\$ 12$ & $\$ 335$ & 337 \\
\hline
\end{tabular}

Note: This table presents descriptive statistics on qualitative uncertainty and on the moments of the subjective belief distributions for individuals for whom we have tax and expectations data. The sample size varies across rows because a few individuals either did not report point forecasts, had a subjective mean of zero, or did not have income in the prior year. In addition, the final row, which reports the mean change in refund relative to the previous year, includes only individuals for whom we have two years of tax returns. 
Table A5: What Drives Uncertainty?

\begin{tabular}{|c|c|c|c|c|c|c|c|c|c|c|c|c|}
\hline & \multicolumn{3}{|c|}{ S.D. of Elicited Beliefs } & \multicolumn{3}{|c|}{ Abs. Change in Refund Amount } & \multicolumn{3}{|c|}{ Abs. Change in MTR } & \multicolumn{3}{|c|}{ Abs. Forecast Error } \\
\hline & $\begin{array}{c}\text { Baseline } \\
\text { (1) }\end{array}$ & $\begin{array}{c}\text { Tax } \\
\text { Determinants } \\
\text { Only } \\
(2) \\
\end{array}$ & $\begin{array}{c}\text { Demographics } \\
\text { Only } \\
\text { (3) } \\
\end{array}$ & $\begin{array}{c}\text { Baseline } \\
\text { (4) } \\
\end{array}$ & $\begin{array}{c}\text { Tax } \\
\text { Determinants } \\
\text { Only } \\
(5) \\
\end{array}$ & $\begin{array}{c}\text { Demographics } \\
\text { Only } \\
(6) \\
\end{array}$ & $\begin{array}{c}\text { Baseline } \\
\text { (7) } \\
\end{array}$ & $\begin{array}{c}\text { Tax } \\
\text { Determinants } \\
\text { Only } \\
(8) \\
\end{array}$ & $\begin{array}{c}\text { Demographics } \\
\text { Only } \\
(9) \\
\end{array}$ & $\begin{array}{c}\text { Baseline } \\
\text { (10) }\end{array}$ & $\begin{array}{c}\text { Tax } \\
\text { Determinants } \\
\text { Only } \\
(11) \\
\end{array}$ & $\begin{array}{c}\text { Demographics } \\
\text { Only } \\
\text { (12) } \\
\end{array}$ \\
\hline Absolute Change in AGI & $\begin{array}{l}10.43 * * \\
(4.517)\end{array}$ & $\begin{array}{l}11.22 * * \\
(4.449)\end{array}$ & & $\begin{array}{c}48.05^{* * * *} \\
(10.83)\end{array}$ & $\begin{array}{c}49.33 * * * \\
(11.05)\end{array}$ & & $\begin{array}{c}0.00462 * * * \\
(0.00156)\end{array}$ & $\begin{array}{c}0.00473 * * * \\
(0.00155)\end{array}$ & & $\begin{array}{l}-0.481 \\
(6.413)\end{array}$ & $\begin{array}{c}1.121 \\
(6.473)\end{array}$ & \\
\hline Has Dependents & $\begin{array}{c}478.5 * * * \\
(50.55)\end{array}$ & $\begin{array}{c}491.4 * * * * \\
(51.24)\end{array}$ & & $\begin{array}{c}554.7 * * * \\
(142.4)\end{array}$ & $\begin{array}{c}652.4 * * * * \\
(138.1)\end{array}$ & & $\begin{array}{c}0.0754 * * * * \\
(0.0208)\end{array}$ & $\begin{array}{c}0.0776 * * * \\
(0.0195)\end{array}$ & & $\begin{array}{c}829.6 * * * * \\
(106.7)\end{array}$ & $\begin{array}{c}845.0^{* * * *} \\
(99.62)\end{array}$ & \\
\hline Change in No. Dependents & $\begin{array}{l}-84.03 \\
(106.7)\end{array}$ & $\begin{array}{l}-78.60 \\
(107.6)\end{array}$ & & $\begin{array}{c}1660.1 * * * * \\
(373.7)\end{array}$ & $\begin{array}{c}1650.8 * * * \\
(375.2)\end{array}$ & & $\begin{array}{c}0.0586 \\
(0.0366)\end{array}$ & $\begin{array}{c}0.0596 \\
(0.0366)\end{array}$ & & $\begin{array}{c}973.0 * * * * \\
(338.4)\end{array}$ & $\begin{array}{c}973.0 * * * \\
(339.1)\end{array}$ & \\
\hline Married & $\begin{array}{l}176.8^{*} \\
(90.30)\end{array}$ & $\begin{array}{l}156.5^{*} \\
(91.82)\end{array}$ & & $\begin{array}{l}-143.2 \\
(244.8)\end{array}$ & $\begin{array}{l}-210.6 \\
(228.3)\end{array}$ & & $\begin{array}{l}-0.0446 \\
(0.0382)\end{array}$ & $\begin{array}{l}-0.0512 \\
(0.0372)\end{array}$ & & $\begin{array}{l}-41.38 \\
(158.1)\end{array}$ & $\begin{array}{l}-38.77 \\
(159.9)\end{array}$ & \\
\hline Change in Filing Status & $\begin{array}{l}-46.52 \\
(111.1)\end{array}$ & $\begin{array}{l}-49.99 \\
(112.7)\end{array}$ & & $\begin{array}{l}-64.57 \\
(415.3)\end{array}$ & $\begin{array}{l}-48.17 \\
(419.5)\end{array}$ & & $\begin{array}{c}0.0350 \\
(0.0428)\end{array}$ & $\begin{array}{c}0.0347 \\
(0.0424)\end{array}$ & & $\begin{array}{l}-537.2 * \\
(301.1)\end{array}$ & $\begin{array}{l}-548.7 * \\
(305.2)\end{array}$ & \\
\hline Received UI during Past Year & $\begin{array}{l}-16.94 \\
(66.57)\end{array}$ & $\begin{array}{l}-19.38 \\
(65.50)\end{array}$ & & $\begin{array}{l}-38.53 \\
(276.3)\end{array}$ & $\begin{array}{c}18.93 \\
(272.4)\end{array}$ & & $\begin{array}{c}0.0199 \\
(0.0367)\end{array}$ & $\begin{array}{c}0.0196 \\
(0.0365)\end{array}$ & & $\begin{array}{l}72.14 \\
(141.2)\end{array}$ & $\begin{array}{c}94.73 \\
(136.2)\end{array}$ & \\
\hline Age 25 or Younger & $\begin{array}{l}-25.92 \\
(42.85)\end{array}$ & & $\begin{array}{c}-177.8^{* * * *} \\
(48.82)\end{array}$ & $\begin{array}{c}-331.4 * * \\
(156.2)\end{array}$ & & $\begin{array}{c}-595.6 * * * \\
(149.5)\end{array}$ & $\begin{array}{l}0.00295 \\
(0.0176)\end{array}$ & & $\begin{array}{l}-0.0274 \\
(0.0228)\end{array}$ & $\begin{array}{l}-112.1 \\
(98.24)\end{array}$ & & $\begin{array}{c}-358.2 * * * \\
(103.2)\end{array}$ \\
\hline Above Age 50 & $\begin{array}{c}-139.6^{* * * * *} \\
(38.26)\end{array}$ & & $\begin{array}{c}-242.8 * * * \\
(43.25)\end{array}$ & $\begin{array}{c}-338.8 * * * \\
(126.3)\end{array}$ & & $\begin{array}{c}-653.4 * * * \\
(160.2)\end{array}$ & $\begin{array}{l}-0.0217 \\
(0.0164)\end{array}$ & & $\begin{array}{c}-0.0546 * * * \\
(0.0166)\end{array}$ & $\begin{array}{c}-196.4 * * \\
(92.50)\end{array}$ & & $\begin{array}{c}-410.8^{* * * *} \\
(99.38)\end{array}$ \\
\hline Any College & $\begin{array}{c}1.789 \\
(42.69)\end{array}$ & & $\begin{array}{l}-20.05 \\
(46.88)\end{array}$ & $\begin{array}{c}11.53 \\
(135.9)\end{array}$ & & $\begin{array}{l}-69.63 \\
(176.1)\end{array}$ & $\begin{array}{c}-0.000560 \\
(0.0163)\end{array}$ & & $\begin{array}{l}-0.00644 \\
(0.0178)\end{array}$ & $\begin{array}{c}122.9 \\
(87.52)\end{array}$ & & $\begin{array}{c}56.51 \\
(97.84)\end{array}$ \\
\hline Female & $\begin{array}{l}-38.92 \\
(38.68)\end{array}$ & & $\begin{array}{c}54.01 \\
(45.54)\end{array}$ & $\begin{array}{c}35.51 \\
(133.6)\end{array}$ & & $\begin{array}{c}128.1 \\
(177.5)\end{array}$ & $\begin{array}{l}-0.00378 \\
(0.0172)\end{array}$ & & $\begin{array}{l}0.0106 \\
(0.0179)\end{array}$ & $\begin{array}{l}-133.9 \\
(83.64)\end{array}$ & & $\begin{array}{c}87.28 \\
(93.99)\end{array}$ \\
\hline Constant & $\begin{array}{c}303.1 * * * * \\
(48.92)\end{array}$ & $\begin{array}{c}222.9 * * * * \\
(31.18)\end{array}$ & $\begin{array}{c}535.0^{* * * *} \\
(51.83)\end{array}$ & $\begin{array}{c}374.5^{* * * *} \\
(136.5)\end{array}$ & $\begin{array}{c}204.5^{* * * *} \\
(70.28)\end{array}$ & $\begin{array}{c}1195.5 * * * \\
(188.1)\end{array}$ & $\begin{array}{l}0.0310^{*} \\
(0.0177)\end{array}$ & $\begin{array}{l}0.0206 * * \\
(0.00996)\end{array}$ & $\begin{array}{l}0.105^{* * * *} \\
(0.0172)\end{array}$ & $\begin{array}{c}672.2 * * * \\
(94.72)\end{array}$ & $\begin{array}{c}553.4 * * * * \\
(60.11)\end{array}$ & $\begin{array}{c}1033.8 * * * \\
(95.90)\end{array}$ \\
\hline Observations & 618 & 618 & 618 & 337 & 337 & 337 & 337 & 337 & 337 & 618 & 618 & 618 \\
\hline R-squared & 0.255 & 0.240 & 0.057 & 0.442 & 0.427 & 0.062 & 0.231 & 0.226 & 0.029 & 0.221 & 0.209 & 0.049 \\
\hline
\end{tabular}

Note: This table investigates the sources of refund uncertainty. Each column presents coefficients from a regression with a different dependent variable, indicated in the header. The dependent variables in columns 1-6 and 10-12 are in dollar units. Absolute Forecast Error is the absolute difference between each filer's refund amount and their mean elicited belief. Absolute Change in AGI is in $\$ 1,000$ units. All specifications include the listed covariates, plus controls for whether a given demographic variable was missing. Robust standard errors are in parentheses. ${ }^{*} \mathrm{p}<0.10,{ }^{* *} \mathrm{p}<0.05,{ }^{* * *} \mathrm{p}<0.01$. 
Table A6: Belief Updating Rates over Prior Year

\begin{tabular}{|c|c|c|c|c|c|c|c|c|c|}
\hline & \multirow{3}{*}{$\frac{\text { Core Sample }}{(1)}$} & \multicolumn{2}{|c|}{ Has Dependents } & \multicolumn{2}{|c|}{ Marital Status } & \multicolumn{2}{|c|}{ Any College } & \multicolumn{2}{|c|}{$\begin{array}{l}\text { Relative to } 2 x \text { Federal Poverty } \\
\text { Line } \\
\end{array}$} \\
\hline & & Yes & No & Married & Not Married & Yes & No & Below & Above \\
\hline & & $(2)$ & (3) & (4) & (5) & (6) & (7) & $(8)$ & $(9)$ \\
\hline \multicolumn{10}{|c|}{ Number of Bins with Positive Probability } \\
\hline $1 \mathrm{Bin}$ & $22.2 \%$ & $24.1 \%$ & $21.3 \%$ & $22.4 \%$ & $22.1 \%$ & $20.6 \%$ & $24.4 \%$ & $20.6 \%$ & $25.0 \%$ \\
\hline 2 Bins & $38.7 \%$ & $39.0 \%$ & $38.5 \%$ & $36.7 \%$ & $38.8 \%$ & $37.3 \%$ & $39.4 \%$ & $40.9 \%$ & $34.8 \%$ \\
\hline 3 Bins & $20.7 \%$ & $16.4 \%$ & $22.7 \%$ & $14.3 \%$ & $21.3 \%$ & $19.4 \%$ & $20.1 \%$ & $21.6 \%$ & $19.2 \%$ \\
\hline 4 Bins & $11.0 \%$ & $11.3 \%$ & $10.9 \%$ & $12.2 \%$ & $10.9 \%$ & $13.5 \%$ & $9.7 \%$ & $10.2 \%$ & $12.5 \%$ \\
\hline 5 Bins & $5.0 \%$ & $7.2 \%$ & $4.0 \%$ & $8.2 \%$ & $4.7 \%$ & $6.3 \%$ & $3.9 \%$ & $4.8 \%$ & $5.4 \%$ \\
\hline 6 Bins & $2.4 \%$ & $2.1 \%$ & $2.6 \%$ & $6.1 \%$ & $2.1 \%$ & $2.8 \%$ & $2.5 \%$ & $2.0 \%$ & $3.1 \%$ \\
\hline \multicolumn{10}{|l|}{ Qualitative Uncertainty } \\
\hline Very Certain & $34.0 \%$ & $30.3 \%$ & $35.7 \%$ & $44.9 \%$ & $33.0 \%$ & $32.5 \%$ & $37.3 \%$ & $36.5 \%$ & $29.5 \%$ \\
\hline Somewhat Certain & $41.7 \%$ & $48.2 \%$ & $38.8 \%$ & $36.7 \%$ & $42.2 \%$ & $38.9 \%$ & $42.7 \%$ & $40.6 \%$ & $43.8 \%$ \\
\hline Not Certain At All & $23.5 \%$ & $21.0 \%$ & $24.6 \%$ & $18.4 \%$ & $23.9 \%$ & $27.0 \%$ & $19.7 \%$ & $22.1 \%$ & $25.9 \%$ \\
\hline \multicolumn{10}{|l|}{ Quantitative Responses } \\
\hline Point Estimate & 1682 & 3520 & 837 & 2469 & 1614 & 1656 & 1726 & 1330 & 2303 \\
\hline \multicolumn{10}{|c|}{ Features of Parametric Distribution } \\
\hline Mean & 1605 & 3365 & 794 & 2378 & 1539 & 1614 & 1618 & 1251 & 2229 \\
\hline Std. Dev. & 426 & 769 & 268 & 648 & 407 & 448 & 413 & 353 & 553 \\
\hline Observations & 618 & 195 & 423 & 49 & 569 & 252 & 279 & 394 & 224 \\
\hline
\end{tabular}

Note: Numbers based on the statistic $\frac{m_{1, i}-r_{0, i}}{r_{1, i}-r_{0, i}}$, for tax filers who also filed their taxes at the tax site in the previous year. As described in Section 4.2, this is the difference between an individual's expectation of this year's refund and their prior year refund, scaled by the change in realized refunds from last year to this year. The three middle columns show the fraction of filers, weighted by the size of refund, for whom the ratio is negative, between 0 and 100, or over 100. Filers for whom the ratio is negative have expectations that moved in the opposite direction (relative to their prior year refund) than their realized refund. Filers for whom the ratio is between 0 and 100 updated in the "correct" direction, but less than 100\%. Filers for whom the ratio is over 100 updated in the "correct" direction, but thought their refund would change more than it did. Mean Ratio (\%) is the mean of this statistic across tax filers in each subgroup. The sample size in the first row differs from that in Column 3 of Table 1 because a few individuals had zero change in refund $\left(r_{1, i}-r_{0, i}\right)$ from the prior year. 
Table A7: Additional Robustness Checks for Borrowing Results

\begin{tabular}{|c|c|c|c|c|c|c|}
\hline & \multirow[b]{2}{*}{$\begin{array}{l}\text { Baseline } \\
\text { (1) } \\
\end{array}$} & \multicolumn{4}{|c|}{ Alternate Belief Distribution: Beta Distribution } & \multirow[b]{2}{*}{$\begin{array}{l}\text { LIML } \\
(6) \\
\end{array}$} \\
\hline & & $\begin{array}{c}\text { Full Sample } \\
(2) \\
\end{array}$ & $\begin{array}{c}\text { No Direct } \\
\text { Deposit } \\
(3) \\
\end{array}$ & $\begin{array}{c}\text { No Savings } \\
(4) \\
\end{array}$ & $\begin{array}{c}\text { Can't Change } \\
\text { Income } \\
(5) \\
\end{array}$ & \\
\hline Expected Refund Amount & $\begin{array}{l}-40.38 \\
(38.07)\end{array}$ & $\begin{array}{l}-54.92 \\
(44.14)\end{array}$ & $\begin{array}{l}-10.04 \\
(48.67)\end{array}$ & $\begin{array}{l}-68.22 \\
(93.92)\end{array}$ & $\begin{array}{l}-33.69 \\
(49.81)\end{array}$ & $\begin{array}{l}-208.5 \\
(155.2)\end{array}$ \\
\hline Subjective Standard Deviation & $\begin{array}{l}259.3 * * \\
(131.5)\end{array}$ & $\begin{array}{c}154.0 \\
(120.6)\end{array}$ & $\begin{array}{c}48.57 \\
(116.0)\end{array}$ & $\begin{array}{l}329.0 * \\
(193.8)\end{array}$ & $\begin{array}{l}224.6^{*} \\
(135.7)\end{array}$ & $\begin{array}{l}1300.1 \\
(924.9)\end{array}$ \\
\hline $\begin{array}{l}\text { Demographics } \\
\text { Tax Determinants }\end{array}$ & $\begin{array}{l}X \\
X\end{array}$ & $\begin{array}{l}X \\
X\end{array}$ & $\begin{array}{l}X \\
X\end{array}$ & $\begin{array}{l}X \\
X\end{array}$ & $\begin{array}{l}X \\
X\end{array}$ & $\begin{array}{l}X \\
X\end{array}$ \\
\hline $\begin{array}{l}\text { Observations } \\
\text { R-squared }\end{array}$ & $\begin{array}{c}359 \\
0.096\end{array}$ & $\begin{array}{c}359 \\
0.092\end{array}$ & $\begin{array}{c}234 \\
0.092\end{array}$ & $\begin{array}{c}91 \\
0.255\end{array}$ & $\begin{array}{c}211 \\
0.114\end{array}$ & $\begin{array}{c}359 \\
---\end{array}$ \\
\hline
\end{tabular}

Note: This table investigates the robustness of the borrowing results in Table 5. The regressions include all of the core sample tax filers for whom we have expectations data and credit report data. Column 1 repeats the main specification in Column 4 of Table 5. Columns 2-5 present present results analogous to those in columns 1-4 in Table 6 where we use the means and standard deviations calculated by fitting beta distributions, rather than normal distributions. The samples in Columns 2-5 are described in Table 6 . Column 6 presents LIML estimates for a regression analogous to that in column 1, where we have instrumented for the subjective standard deviation with indicators for our two qualitative measures of uncertainty. The demographic controls include controls for whether a filer is female, over 50, a college graduate, married, or has dependents. The tax determinants include controls for the (absolute value of the) change in AGI, a dummy for any change in the number of dependents, a dummy for a change in filing status, and a dummy for whether the filer received UI this year. Robust standard errors are in parentheses. ${ }^{*} \mathrm{p}<.1^{* *} \mathrm{p}<0.05^{* * *} \mathrm{p}<0.01$ 


\section{B For Online Publication: Data and Empirical Setting}

This appendix provides more information on the tax filer surveys, as well as information on the context in which we conducted these surveys.

\section{B.1 Expectations Survey}

The expectations survey consisted of four questions, printed on the next page. The survey was administered by the financial guides at the tax site.

The first question produces a point estimate of individuals' beliefs. The second question measures individuals' qualitative uncertainty: whether they are "not sure at all," "somewhat sure," or "very sure" that their refund would fall within a \$1,000-interval around the number they reported in the first question. The third question was used to measure labor income flexibility.

The fourth question elicits probabilistic beliefs. The number of bins was chosen in coordination with the VITA partner in order to balance the need to run the survey quickly with the desire to obtain richer information on individuals' beliefs. The boundaries of the bins were chosen using data on the distribution of refunds for filers at the site in the previous year, so that roughly an equal number of actual refunds would fall in each bin, with a smaller number in the two tail bins. In our core sample, the middle four of these six bins ultimately covered $24 \%, 19 \%, 24 \%$, and $13 \%$ of tax filers' actual refunds, while the two tail bins covered $20 \%$ of tax filers' actual refunds. 
1) If you get a tax refund this year, how much do you think it will be? Please choose an amount:

$\$$

(Financial Guide volunteer: please write $\$ 500$ above this number, and $\$ 500$ below this number, in the two blank lines in the question below)

2) How sure are you that your refund will be between $\$$ and $\$$ ? Please circle one:

NOT SURE AT ALL

3) Suppose you want to make some extra money by working more hours next week. Do you think you could you get your manager/supervisor to schedule you for more hours?

\section{YES}

NO

I AM NOT WORKING RIGHT NOW

I AM NOT PAID HOURLY

4) We have one final question about your tax refund. Below we show six possible amounts that your refund could be (for example, "between $\$ 1000$ and $\$ 2500 "$ "). For each of the six possibilities, please say what is the "percent chance" that you think your refund could be that amount:

\section{Could my refund be... $\quad$ (Please Enter \% Chance for Each)}

\begin{tabular}{|r|r|}
\hline Over $\$ 5000$ & $\%$ \\
\hline Between $\$ 2500$ and $\$ 5000$ & $\%$ \\
\hline Between $\$ 1000$ and $\$ 2500$ & $\%$ \\
\hline Between $\$ 500$ and $\$ 1000$ & $\%$ \\
\hline Between $\$ 0$ and $\$ 500$ & $\%$ \\
\hline Negative: I will owe taxes & $\%$ \\
\hline
\end{tabular}




\section{B.2 Tax Environment}

We conducted our survey in spring 2016, when filers were filing their 2015 tax year returns. Figure A5 shows that there were no major changes in either the federal or state tax schedule that would have resulted in large refund changes between tax years 2014 and 2015.

Figure A5: Imputed Refund Changes

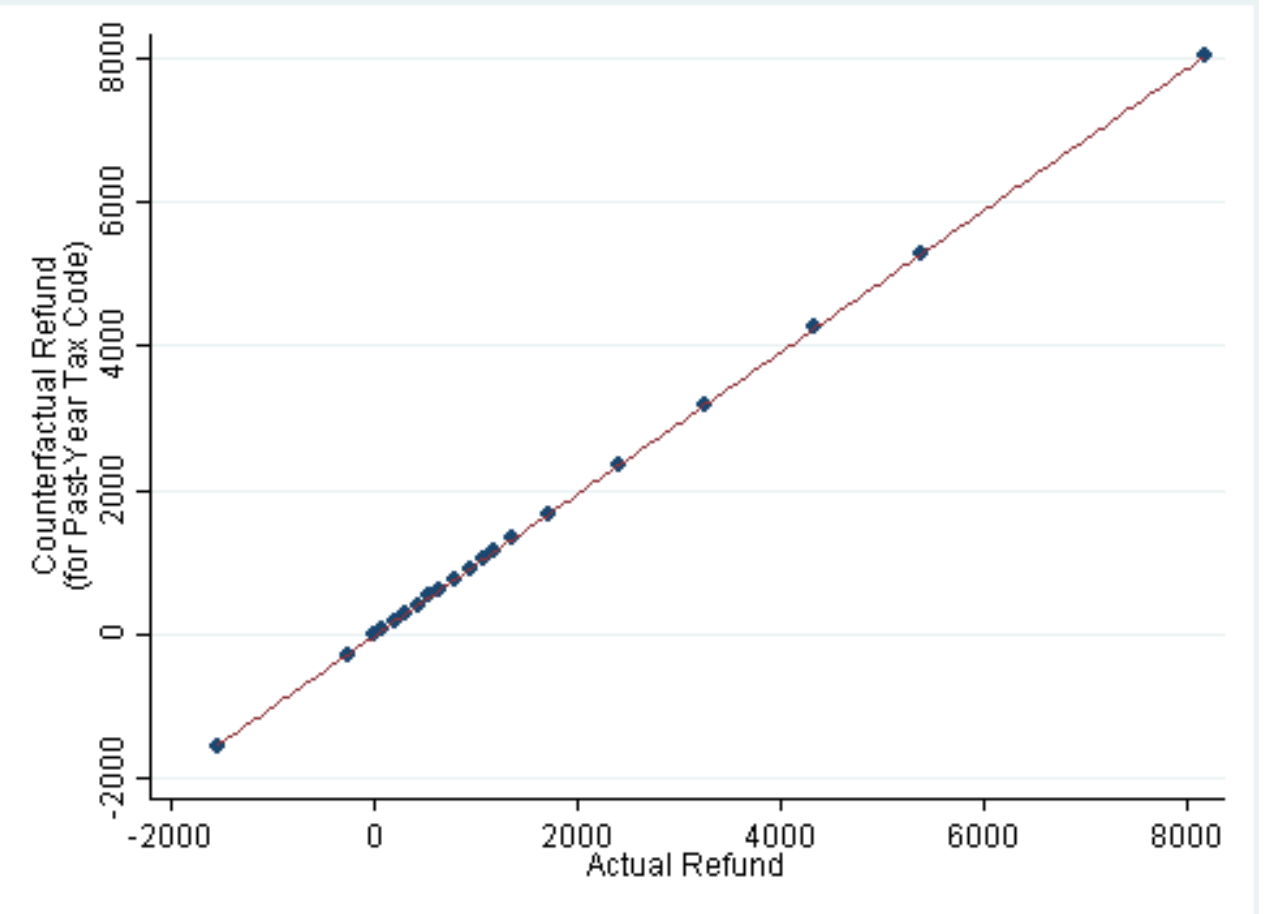

Note: This figure plots a binned scatterplot of the refund an individual would have received under the 2014 tax rules (y-axis), relative to what they received under the 2015 schedule. The 2014 refunds were calculated using NBER TAXSIM (Feenberg and Coutts, 1993).

This is not surprising, because both the federal and state income schedules remained fairly stable between 2014 and 2015. The EITC and CTC also saw no major changes. 


\section{Updating Model}

Suppose filers' prior beliefs $\left(m_{0, i}\right)$ are normally distributed and centered at their prior year refund $\left(r_{0, i}\right)$ with precision $h_{0}\left(X_{i}\right)$, and that filers receive noisy signals of the change in their refund, $\Delta r_{i}+\epsilon_{i}$, where $\epsilon_{i} \sim \mathcal{N}\left(0,1 / h_{\epsilon}\left(X_{i}\right)\right)$. Filers' Bayesian posterior beliefs $\left(m_{1, i}\right)$ and "updates" $\left(m_{1, i}-r_{0, i}\right)$ are then given by:

$$
\begin{gathered}
m_{1, i}=r_{0, i}+\underbrace{\frac{h_{\epsilon}\left(X_{i}\right)}{h_{0}\left(X_{i}\right)+h_{\epsilon}\left(X_{i}\right)}}_{\equiv I\left(X_{i}\right)}\left(\Delta r_{i}+\epsilon\right) \\
\underbrace{m_{1, i}-r_{0, i}}_{\text {update }}=\left(r_{1, i}-r_{0, i}\right) \times \underbrace{I\left(X_{i}\right)}_{X_{i}^{\prime} \beta}+\epsilon \times I\left(X_{i}\right)
\end{gathered}
$$

The amount that filers update depends on the relative precision of their prior and signal. In our regressions we parameterize the updating rate $I\left(X_{i}\right)=X_{i}^{\prime} \beta$. The primary restriction is that conditional on observables, households update towards their signal at the same rate relative to their prior - in other words, they have the same ratio of their signal and prior precisions. In practice, we view our estimates as capturing an average updating rate among filers in a particular group, averaging over any possible unobserved heterogeneity in updating rates.

\section{Computing Compensating Variation}

In order to calculate compensating variation for each individual, we have to make assumptions about the interest rate, discount rate, take-home pay, distribution of refund amounts, and form of the utility function.

- Take-home Pay: Take-home pay in each period, $c_{0, i}, c_{1, i}$, is equal to the individual's quarterly take home pay (adjusted gross income, minus withholding)/4.

- Distribution of $y$ : We use the elicited belief distribution as our measure of $F(y)$.

- Credit Constraints: The borrowing limit is $c_{i, 1}+E[y]$. A few households choose negative debt (positive savings) given expectations of a negative refund. Given the high levels of baseline non-installment debt in this population, we interpret savings as a marginal repayment of non-installment (e.g., credit card) debt.

- Consumption Commitments: Individuals must consume at least $\$ 100$ each period.

- Interest Rate: Individuals can borrow or save at a quarterly interest rate of $R=1.05$. This is a realistic credit card interest rate for this population.

- Discount Rate: Individuals discount the future using $\beta=.98$. 


\section{Algorithm}

We calculate the compensating variation for each individual. For each functional form for utility, we calculate $\mathrm{CV}$ as follows:

- For each $s$ in $1, \ldots, B$

1. Draw realizations of the refund amount $y_{i s}\{s=1, \ldots, S\}$ using the elicited belief distribution $N\left(\mu_{i}, \sigma_{i}^{2}\right)$.

2. Calculate $C V_{i}^{n u}$

3. Calculate $C V_{i}^{d}$ assuming $y=E[y]$.

- Save the average realization of $C V_{i}^{n u}$ and $C V_{i}^{d}$ for each individual.

We average over individuals to report the mean $C V^{n u}$ and $C V^{d}$ for a given utility function and set of preference parameters. These results are presented in Table 7 and Figure 4 . 


\section{E For Online Publication: Belief Distributions}

\section{E.1 Normal Distributions}

Our baseline estimates use beliefs fitted to normal distributions. Our procedure for fitting these beliefs is provided in Section 3 in the main text. As described in that section, our procedure fits reported beliefs to:

$$
\min _{\mu, \sigma} \sum_{x \in \mathcal{X}_{i}}\left[p_{x, i}-\Phi\left(\frac{x-\mu}{\sigma}\right)\right]^{2}+\left(\max \left\{0,1+\Phi\left(\frac{x-\mu}{\sigma}\right)-\Phi\left(\frac{\bar{x}-\mu}{\sigma}\right)-\alpha\right\}\right)^{2}
$$

Example For example, suppose a filer reports a "best guess" of $\$ 400$ and says that there is a $60 \%$ chance they will receive between $\$ 0$ and $\$ 500$ and a $40 \%$ chance they will receive between $\$ 500$ and $\$ 1000$. This corresponds to $\mathcal{X}=(\$ 400, \$ 500), p=(0.5,0.6)$, and $(\underline{\mathrm{x}}, \bar{x})=$ $(\$ 0, \$ 1000)$. The middle plot in Figure A2 shows the normal distribution which best fits this elicitation. The first and third plots present analogous figures for filers who placed positive probability on three and one bins, respectively. In the single-bin case, equation 1 does not pin down $\sigma$, so we restrict the mass outside the bin to equal exactly $\alpha$.

\section{E.2 Beta Distributions}

Fitting beliefs to normal distributions has the advantage of being consistent with the updating model we use in Section 4. However, normal distributions are also restrictive. For this reason, much of the literature on subjective expectations has fit probabilistic beliefs to beta distributions. Beta distributions are flexible, and allow for belief distributions that are not symmetrical and that have finite support.

In order to probe the robustness of our empirical results, we compare our baseline measures of uncertainty to those we would obtain if we fit beliefs to beta distributions.

\section{E.2.1 Fitting Beliefs}

As before, our procedure for fitting beliefs depends on the number of bins on which the respondent placed positive probability. Single bin reports are fit with a scalene triangle; the support is the full bin, and the mode is the point estimate. In this case, we depart from Engelberg et al. (2009) by using additional information from the respondent's point estimate and by not constraining the estimated beta densities to be single-peaked. 
The two-bin reports are fit with an isosceles triangle with the widest possible support that is consistent with the probabilities for each bin. These sets of assumptions uniquely pin down a distribution for one- and two-bin responses. For three or more bins, we follow Engelberg et al. (2009) in fitting a beta distribution to the reported quantiles. The maximum refund amount was a little below $\$ 20,000$, and the lowest refund amount was approximately $-\$ 500$ (the tax filer had $\$ 500$ due). We take these two values as the endpoints of the support of the highest (over $\$ 5,000$ ) and lowest (negative) bins.

The triangle distributions are exactly identified and fit using analytical formulas. To fit the beta distributions, we follow Engelberg et al. (2009) and minimize the sum of squared differences between the reported cumulative probabilities at each point in the distribution's support and those of a beta distribution with the same support. Let $\mathcal{X}$ denote the support points of the response to the probabilistic survey question. Let $Z$ denote a beta-distributed random variable governed by parameters $(\alpha, \beta)$ and normalized to have support on $\mathcal{X}$. Finally, let $p_{x}$ denote the reported cumulative probability at each point $x \in \mathcal{X}$. We find the $\left(\hat{\alpha}_{i}, \hat{\beta}_{i}\right)$ for the elicited distribution from each individual $i$ which solves

$$
\min _{\alpha, \beta} \sum_{x \in \mathcal{X}_{i}}\left[p_{x, i}-P(Z \leq x \mid \alpha, \beta)\right]^{2}
$$

\section{E.2.2 Comparison with Normal Beliefs}

Figure A7 compares the means and standard deviations from the normal and beta fitted belief distributions. The first panel shows that the mean beliefs track each other closely; the slope of the fitted regression line lies nearly on top of the 45-degree line. The second panel shows that the standard deviations of uncertainty also track each other closely. However, we obtain larger standard deviations when using the beta distribution. This is especially true for individuals with high absolute levels of uncertainty. This is because the more flexible beta distribution allows us to capture uncertainty that is not "symmetric." By contrast, the normal distribution smooths out uncertainty that leads to skewness in the distribution.

Table A3 presents descriptive statistics on the means and standard deviations of different groups of tax filers under different parametric assumptions. Dropping individuals that put $50 / 50$ probability on two bins does not affect the mean or standard deviation meaningfully. Dropping individuals who placed a hundred percent probability on a single bin reduces the standard deviation somewhat, especially when we use the beta distribution. Our estimates using the normal distribution are less sensitive to the choice of sample. 
Figure A6: Fitting Beliefs to Beta Distributions
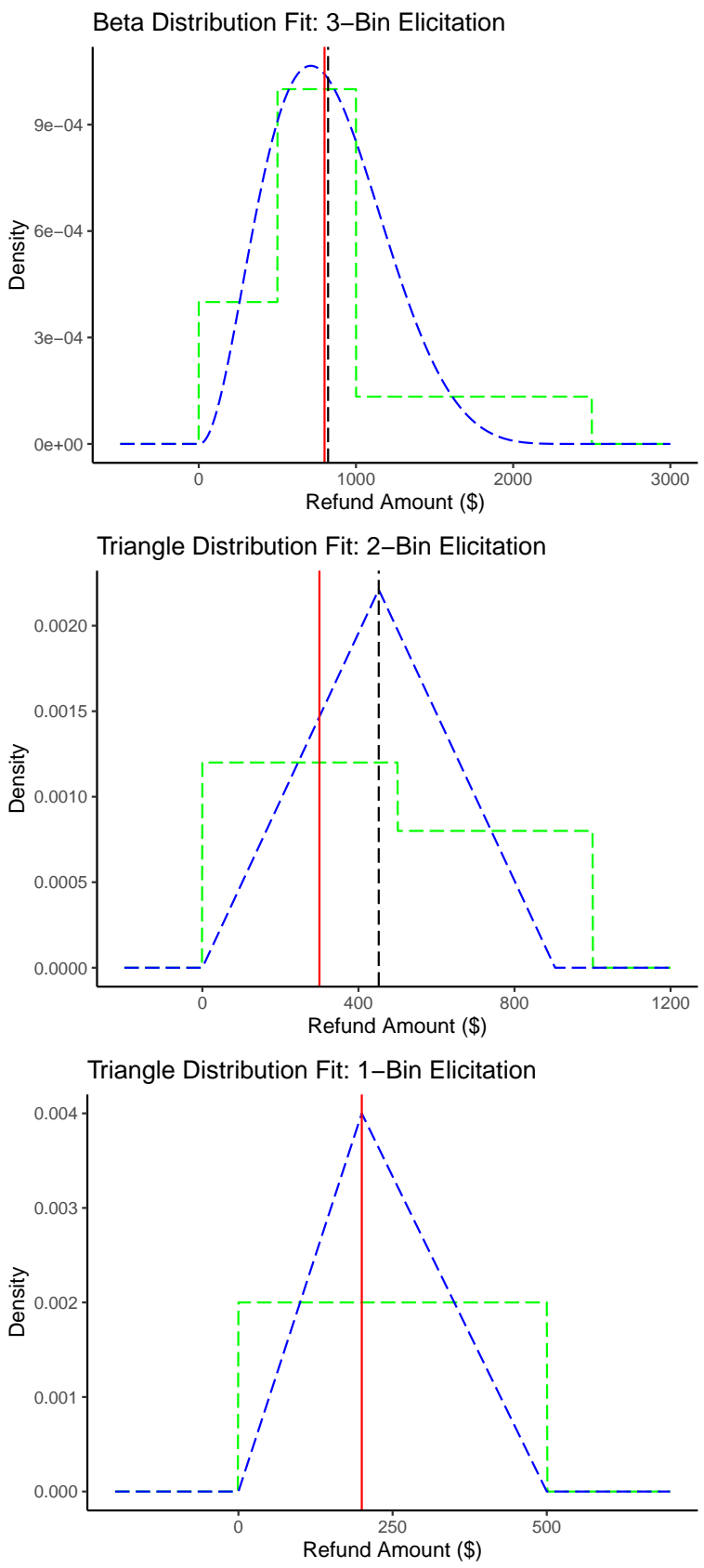

Note: This figure shows how we fit probabilistic beliefs to beta distributions if the individual places positive mass in 3 or more bins (top), in 2 bins (middle) or 1 bin (bottom). Solid lines denote data; dashed lines denote fitted distributions. The green dashed lines report the distribution of beliefs, assigning a uniform density over the density in each bin. The red line denotes the point expectation. The dashed blue curves show the density of the fitted distribution and the dashed black line shows the mean of this distribution. More information on how we fit beliefs to beta distributions is provided in Appendix Section E. Graphs describing how we fit beliefs to normal distributions are provided in Figure A2. Table 2 presents descriptive statistics on the fitted beliefs. 
Figure A7: Distributional Assumptions for Beliefs

\section{A. Mean Expectation}

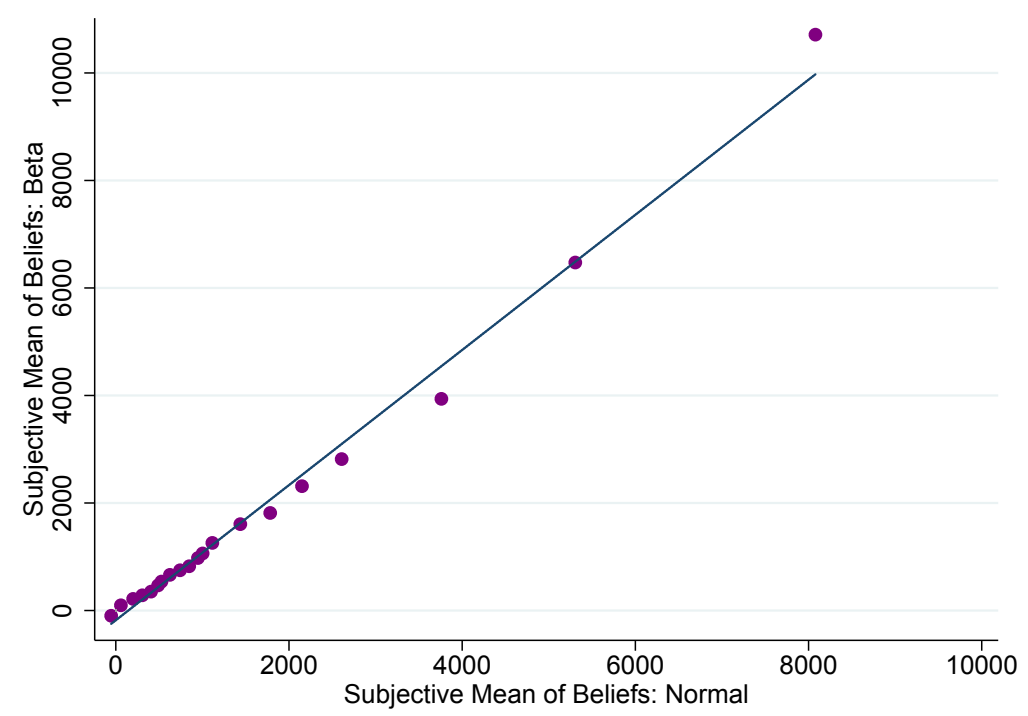

B. Subjective Standard Deviation

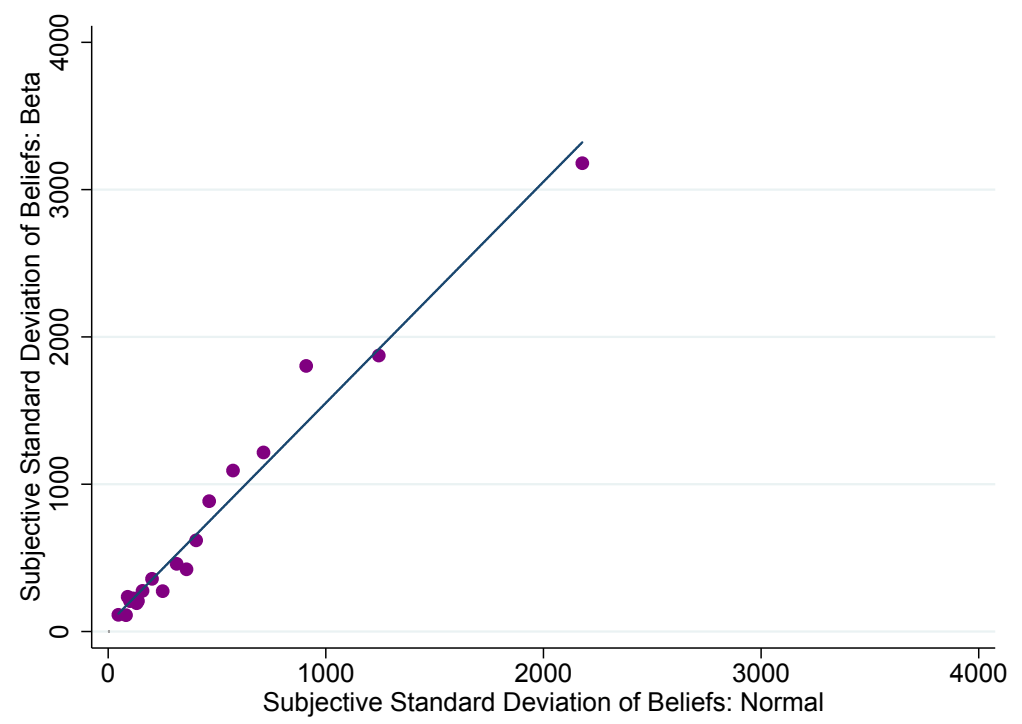

Note: This figure plots the fitted mean beliefs (panel A) and fitted standard deviations of beliefs (panel B) from a normal distribution against those from a beta distribution. Section 3 describes how we fit normal distributions; Appendix Section E describes how we fit beta distributions. 